University of Redlands

\title{
A Parking Model for Roseville, California
}

\author{
A Major Individual Project submitted in partial satisfaction of the requirements \\ for the degree of Master of Science in Geographic Information Systems \\ by \\ Korosh Dabestani \\ Mark Kumler, Ph.D., Committee Chair \\ Fang Ren, Ph.D.
}

March 2011 
A Parking Model for Roseville, California

Copyright (C) 2011

by Korosh Dabestani 
The report of Korosh Dabestani is approved.

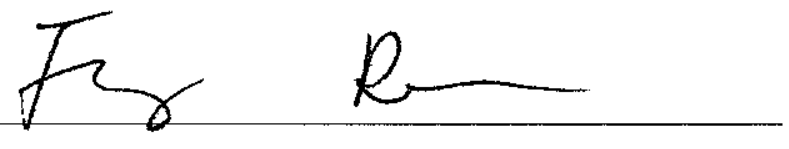

Fang Ren, Ph.D.

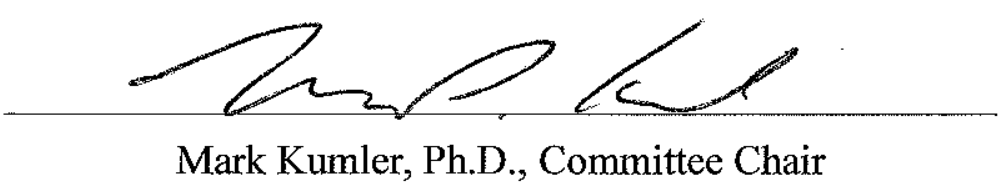

March 2011 



\section{Acknowledgements}

I thank Ahura Mazda for enabling me to achieve all that I have achieved.

To my parents, Gol and Khosro Dabestani, for their never-ending support and encouragement. To my fiancé, Neda, for her patience, support, and love through the duration of the MS GIS program. To my family, for all their support.

I am deeply grateful to my advisor, Mark Kumler, Ph.D., for his detailed and constructive comments, and for his important support and guidance throughout this work. I would like to thank Fang Ren, Ph.D., for being in my committee.

I would like to thank Steve Rhyne and Fehr \& Peers Inc., for providing me with my project topic and project data.

I would like to thank remaining faculty and staff in the MSGIS program, especially Debra Riely, Ruben Ortiz, and Steve Paplanus for their assistance and help at all hours of the day and over weekends was invaluable. I am also grateful to Gina for her providing detailed edits of my reports.

Most importantly, I would like to thank all my friends for their enjoyable presence in my life. 



\begin{abstract}
A Parking Model for Roseville, California

by

Korosh Dabestani

A parking spot is a point of connection between the persons inside a car and their desired activity. When people can not find parking spots, they perceive that there is a significant parking problem. This project considered parking issues facing downtown Roseville, California. To address this issue, this project provided two tools. First, the project provided a tool with a friendly interface for calculating parking demand for each parcel based on its land use, and for different time periods. Second, the project provided a tool for assigning each parking space to the parking demand within specific time period using ArcGIS Network Analyst extension. The tool used a location-allocation technique with random selection. These tools enable the user to model different scenarios for better decision making.
\end{abstract}





\section{Table of Contents}

Chapter 1 - Introduction ................................................................................................ 1

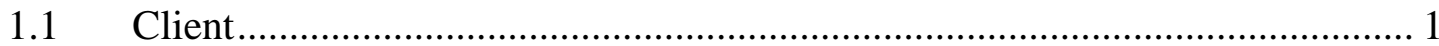

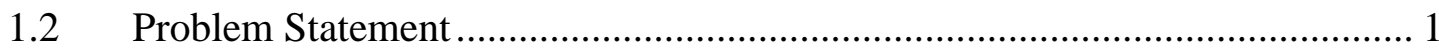

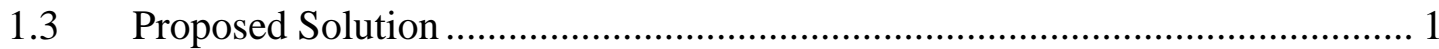

1.3.1 Goals and Objectives .......................................................................... 1

1.3.2 Scope

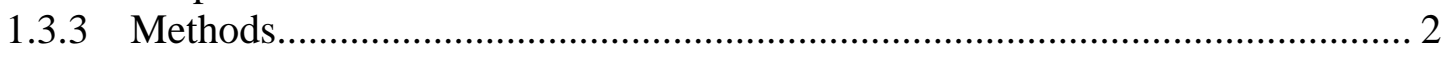

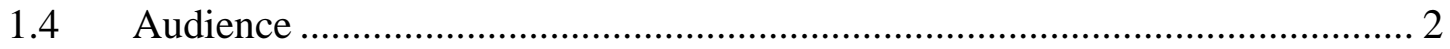

1.5 Overview of the Rest of this Report ......................................................... 2

Chapter 2 - Background and Literature Review .............................................................. 3

$2.1 \quad$ Parking Modeling............................................................................... 3

$2.2 \quad$ Parking Demand..................................................................................... 3

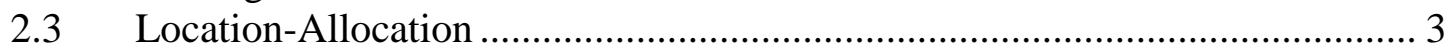

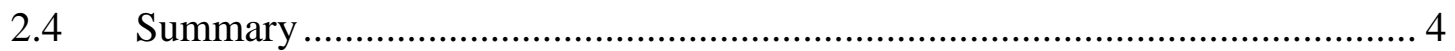

Chapter 3 - Systems Analysis and Design....................................................................... 5

$3.1 \quad$ Problem Statement ......................................................................... 5

3.2 Requirements Analysis ………………………………………………. 5

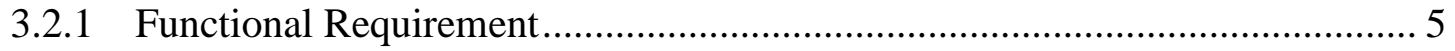

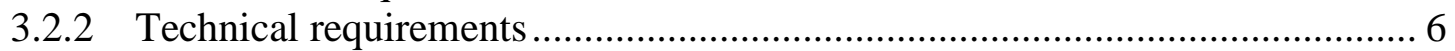

3.2.3 Operational Requirements ..................................................................... 7

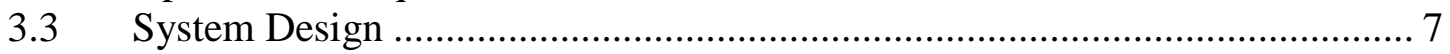

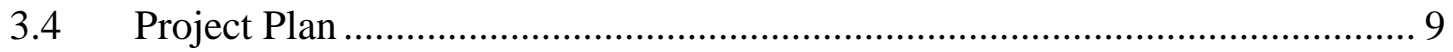

3.4.1 Research and Requirement analysis.......................................................... 9

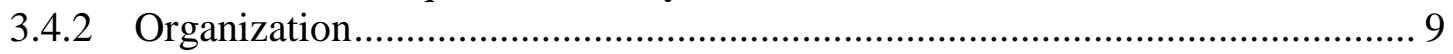

3.4.3 Analysis and Implementation ................................................................ 10

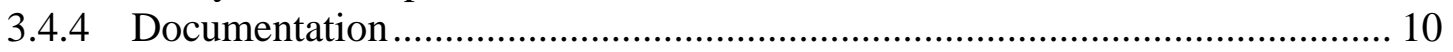

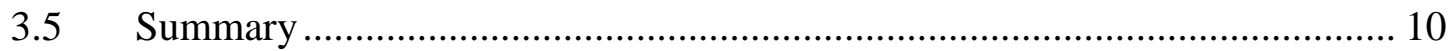

Chapter 4 - Database Design................................................................................................... 11

4.1 Conceptual Data Model .......................................................................... 11

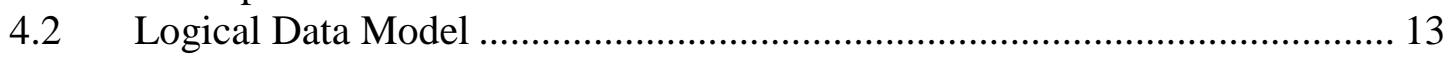

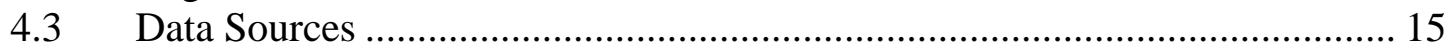

4.4 Data Scrubbing and Loading ……………………................................. 15

4.4.1 Landuse feature class .......................................................................... 15

4.4.2 Parking_Inventory feature class................................................................. 15

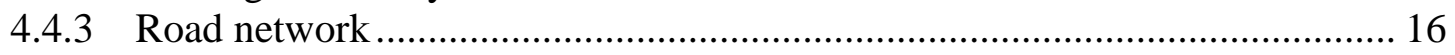

4.4.4 Parking demand tables ............................................................................. 16

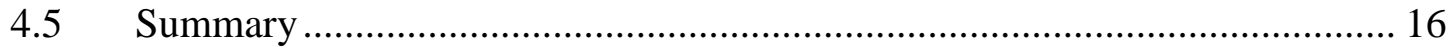

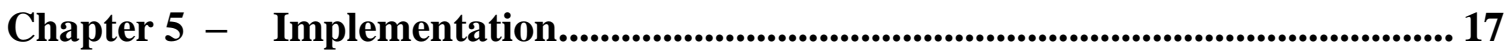

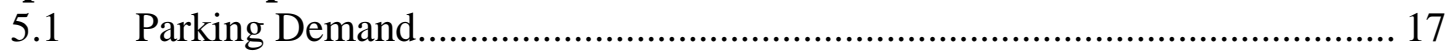

5.1.1 Implementation of SQL Express................................................................. 17

5.1.2 Parking demand application........................................................................ 18

5.1.3 Parking demand interface …………………………………………….... 20 


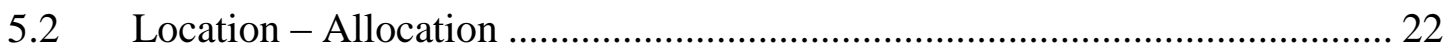

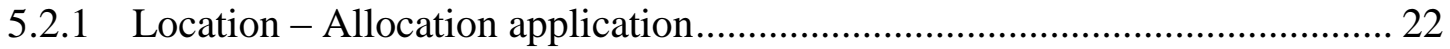

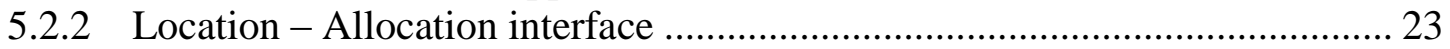

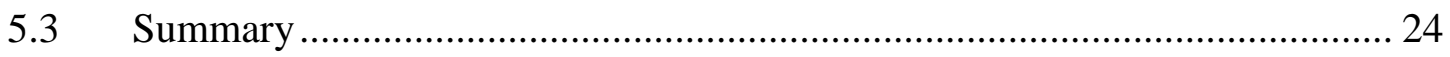

Chapter 6 - Results and Analysis....................................................................................... 25

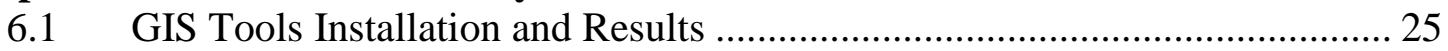

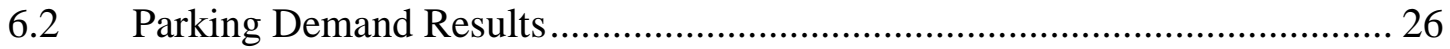

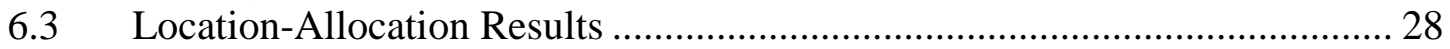

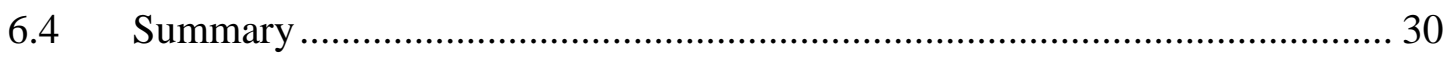

Chapter 7 - Conclusions and Future Work ............................................................... 33

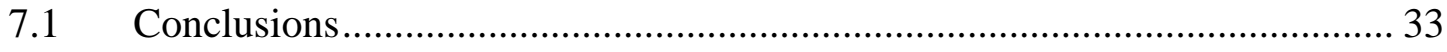

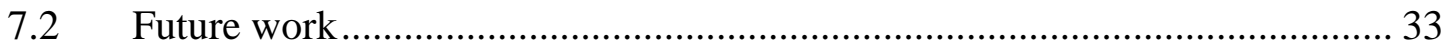

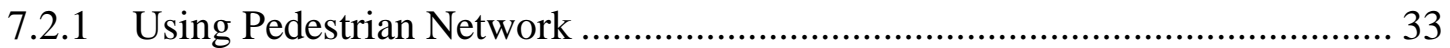

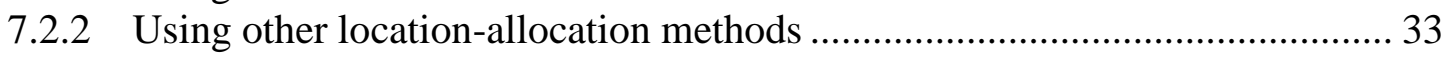

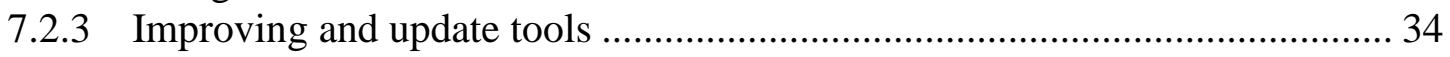

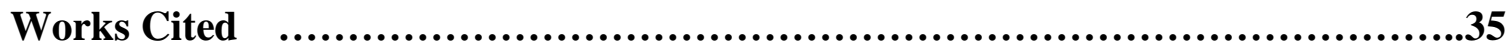

Appendix A. Location-Allocation ....................................................................... 37 


\section{Table of Figures}

Figure 3-1: $\quad$ System Architecture .................................................................... 8

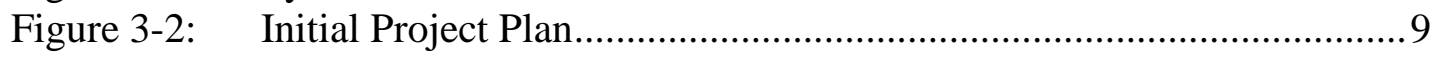

Figure 4-1: $\quad$ Parking demand conceptual data model ............................................ 12

Figure 4.2: $\quad$ File geodatabase conceptual data model.......................................... 12

Figure 4-3: Geodatabase logical data model.................................................... 13

Figure 4-4: $\quad$ Parking demand logical model.................................................... 14

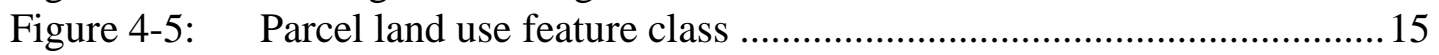

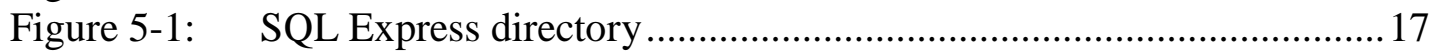

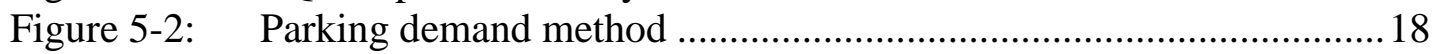

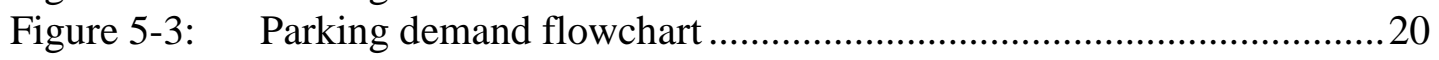

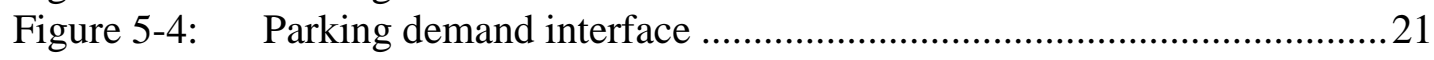

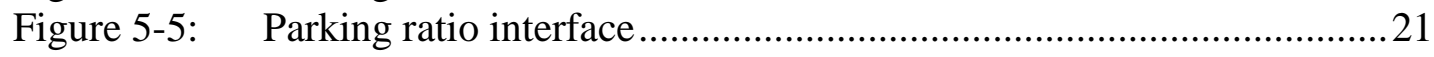

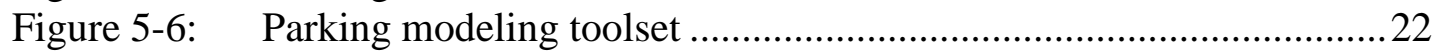

Figure 5-7: $\quad$ Location - Allocation method ....................................................23

Figure 5-8: Location- Allocation interface ........................................................ 24

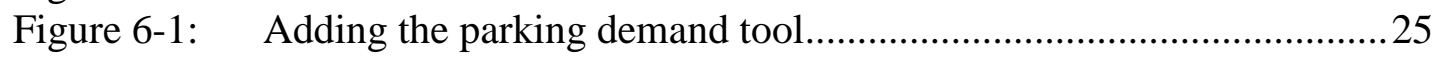

Figure 6-2: Adding the Location-Allocation tool ............................................26

Figure 6-3: The result of parking demand tool at 8 PM in January ......................27

Figure 6-4: Location-Allocation network dataset output.....................................28

Figure 6-5: Result of Location-Allocation tool within 5 minute .........................29

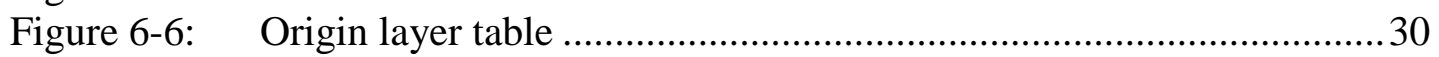

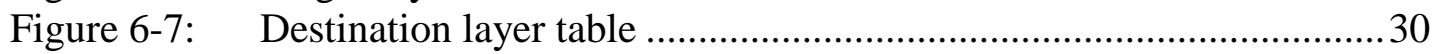

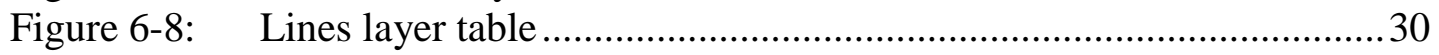





\section{List of Tables}

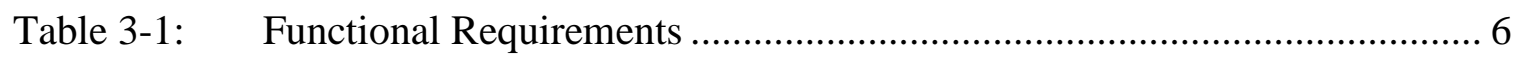

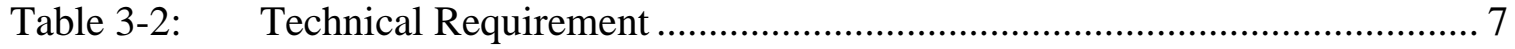

Table 5-1: Query syntax from SQL Server .......................................................... 19 



\section{List of Acronyms and Definitions}

CBD Commercial Business District

GIS Geographic Information System 



\section{Chapter 1 - Introduction}

Frustrated drivers try to find a parking spot closer to their destination around commercial business districts (CBD). They spend a lot of time driving around blocks and looking everywhere to find a parking spot.

Planners design enough parking for CBD, but with increasing population, many cities face the problem of heavy traffic, inadequate parking, and the cost of a parking is high. Therefore, parking spaces are limited and demand is increasing every day. Many drivers consider access time and search time when they are trying to find parking spots.

\subsection{Client}

Fehr \& Peers Inc. is a private company that provides transportation planning and traffic engineering services to public and private clients. Their emphasis is on the development of creative, cost-effective, and result-oriented solutions to planning and design problems associated with all models of transportation. Its services include: landuse/transportation planning, parking, traffic operation and simulation, traffic planning, travel demand forecasting, and intelligent transportation systems.

The main point of contact for this project was Steve Rhyne. He is a GIS professional working at Fehr \& Peers as a GIS/Communication Specialist. He provided the parking demand model and a geodatabase containing all the necessary data for the study area.

The study area includes city of Roseville. Roseville is a city in Placer County, California, United States, located in the metropolitan area of Sacramento.

\subsection{Problem Statement}

Fehr \& Peers Inc. needed to add another parameter, walk-time between each parcel and each parking space, to their existing parking demand model. In addition, the client needed to make the model more flexible, whereby the user may prioritize the different land uses, adjust the walking time thresholds, and select time of day or month.

\subsection{Proposed Solution}

Fehr \& Peers' parking demand model no longer works for them because the model is task oriented, and they cannot use the model on other geographic areas. Adding flexibility and functionality to the model will enable the client to use this model for different areas.

The proposed solution for this problem was to use network analysis between parking spaces and parcels. In addition, the program would provide an interface for the model so that the client could use the model for different areas.

\subsubsection{Goals and Objectives}

The goal of this project was to help Fehr \& Peers to improve the model for estimating unsatisfied parking demands and supplies for each area. Under this general goal, two objectives were established. The main objective was to add a walk-time threshold to the model by using network analysis. The second objective was to make the model more 
flexible so users have the ability to assign parking rates to each land use value or provide a list of existing land use values from the parcel database.

\subsubsection{Scope}

The main intention of the project was to produce two major deliverables. First, it provided the client's staff with tools to run different scenarios for calculating unsatisfied parking demands and supplies. This was accomplished by designing a customized user interface in ArcGIS that provided ability for staff to change parameters. Second, the model used network analysis to connect parking demands and supplies, and then uses the allocation model on an origin-destination matrix to get the optimum number of connections within time thresholds.

This project did not make or design the pedestrian network dataset; it used the street network dataset. In addition, this project did not study drivers' behavior to choose parking.

\subsubsection{Methods}

The customized user interface was designed and developed for the parking demand model. The client provided the parking demand model, which included five separate tables containing variables for different land uses, time of day, and day of the week. The program then used network analysis to connect parking demand to parking supplies. using the origin-destination matrix, the program performed a random selection of connections between parking demands and supplies within time thresholds from the origin-destination matrix. Then the program calculated unsatisfied parking demands and supplies and imported them as a feature class and table to ArcGIS.

\subsection{Audience}

The audience for this project was the staff of Fehr \& Peers who are GIS analysts and planners. The GIS department supports the Transportation and Urban Design department by providing GIS services.

\subsection{Overview of the Rest of this Report}

The structure of this paper is as follows. Chapter 2 provides a literature review of relevant topics that influenced the development of this project. Chapter 3 discusses system analysis and design. Chapter 4 provides a description of the database design. Chapter 5 gives a detailed description of the project's implementation. Chapter 6 discusses the result and analysis of using the developed tools. Chapter 7 concludes with a summary and discussion of future work. 


\section{Chapter 2 - Background and Literature Review}

This project deals with a special part of GIS, known as GIS Transportation (GIST). This literature review deals with parking modeling and its relationship with parking demand, pedestrian, and location-allocation analysis.

First, the literature review will discuss parking modeling and its components, which are parking demand, supply, and their relationship to one another. Second, different methods for calculating parking demand will be shown. Third, location-allocation problems are described, in addition to the methods used in this project.

\subsection{Parking Modeling}

Parking modeling is a subject that has been receiving increasing attention in transportation due to increasing parking problems in commercial business districts. Parking problems occur when there are not enough parking supplies for cars. Parking modeling is used in transportation to demonstrate the relationship between parking demands and supplies (Young, 2000). There are three separate parts to this definition of parking modeling: parking demand, parking supply, and the relationship between them. In this project, parking supplies refers to off-street parking, in-street parking, and illegal parking. Parking demand and the relationship between parking demand and supply are described in the next two sections.

\subsection{Parking Demand}

"The demand for parking is an example of what economists call a 'derived demand.' Parking is not an end in itself; it simply allows people access to the places where they want to shop, play, or work" (Voith, 1998). Urban designers normally assign a minimum parking requirement for every land use. The minimum parking requirement should provide enough available free parking for rush times. Different models have been developed to calculate the minimum parking requirement (Institute of Transportation Engineers, 2010; Wong, Tong, Lam, \& Fung, 2000).

There are some problems with using these models. The demand for parking is changing over time. For example, if more people are attracted to the commercial business districts than to other retail, recreational, or business districts, the amount of parking demand increases. The models provided for calculating a minimum parking demand are not completely accurate. There are different ways to solve the problem; one of them is to adjust the model (Shoup, 1999).

\subsection{Location-Allocation}

When people drive to commercial business districts for shopping, work, or play, there are different key elements that help them to make decisions about parking selection. These key elements are access time (driving from home to the destination), egress time (distance from parking space to the parking demand), parking policy, and waiting time. Egress time is one of the most important choices for customers when choosing a parking space (Axhausen \& Polak, 1991; Van Der Waerden, Oppewal, \& Timmermans, 1993). 
In this project, each parking demand was connected to a parking supply using a pedestrian network within a time threshold. There are different ways to connect parking demands and supplies to each other (Cooper, 1963; Schietzelt \& Densham, 2003). In most literature about location-allocation models, researchers try to decrease the costs between origin-destination, such as distance, or they try to optimize other costs like time. Using the optimization method for location and allocation is not feasible because of the number of parking demands and supplies (Love \& Juel, 1982). In this project, we chose the connections between parking demands and supplies within a time threshold, so each parking demand was assigned to a parking supply, and the cost between them was not important. For solving the location-allocation problem, this project used a random selection of connections between parking demands and supplies (Cooper, 1964; Love \& Juel, 1982).

\subsection{Summary}

This chapter highlighted the important and relevant work done in other fields of study. For this project, the most important elements of previous studies are parking modeling, parking demand, and location-allocation. The Parking Modeling section highlighted different components of parking modeling. The Parking Demand section discussed different methods for calculating parking demand and the problems with those methods. The Location-Allocation section looked at choice behavior of customers when they are looking for parking. In addition, the section looked at different location-allocation models. 


\section{Chapter 3 - Systems Analysis and Design}

Chapter 3 discusses the system and the data needed to solve the problem. This includes a description of the problem, details of the system requirements, a summary of the system architecture, and an outline of the project plan for system development.

\subsection{Problem Statement}

Knowledge of the amount of unsatisfied parking demands and supplies helped Fehr \& Peers Inc. to increase parking supplies by assigning a sufficient amount of parking spaces. It also helped Fehr \& Peers Inc. to decrease parking demand by changing land use. Fehr \& Peers Inc. desired an easy-to-use system that would allow staff members to analyze parking demands and supplies by incorporating land use data and an analysis of the road network. The system allows staff members to calculate parking demands for different times of the day, week, and year. The system connects parking demands to supplies within a time threshold, using network analysis to calculate unsatisfied parking demands and supplies.

\subsection{Requirements Analysis}

Before beginning the system design, it was important to specify the requirements of the project to ensure the best system. A list of requirements was established after several meetings and written communications with the client. Two kinds of requirements were recognized: functional and nonfunctional. In the functional requirements, we defined what the system does, and then in the nonfunctional requirement, we defined how well the system performs. The nonfunctional requirements included additional technical and operational requirements.

\subsubsection{Functional Requirement}

The functional requirements of the project were determined after discussions with the client. The first functional requirement was to calculate parking demand with the formulae and tables provided by the client. The second function was to make an interface that provides functionality for users to try different scenarios for calculating parking demand. The third function was to connect parking demand and supplies through network analysis. The fourth function was to calculate unsatisfied parking demands and supplies. (See Table 3-1) 


\section{Table 3-1: Functional Requirements}

\begin{tabular}{|l|l|}
\hline Function & Description \\
\hline Calculate Parking Demand. & $\begin{array}{l}\text { The client provided tables that calculate } \\
\text { the amount of parking demand and these } \\
\text { tables are stored in the file geodatabase. }\end{array}$ \\
\hline $\begin{array}{l}\text { Add functionality so the client has the } \\
\text { ability to change parameters to try } \\
\text { different scenarios. }\end{array}$ & $\begin{array}{l}\text { The interface design contained parameters } \\
\text { that the client could change. }\end{array}$ \\
\hline $\begin{array}{l}\text { Connect parking demands to parking } \\
\text { supplies. }\end{array}$ & $\begin{array}{l}\text { Network analysis was used to connect } \\
\text { parking demands to parking supplies. }\end{array}$ \\
\hline $\begin{array}{l}\text { Calculate unsatisfied parking demands } \\
\text { and supplies. }\end{array}$ & $\begin{array}{l}\text { The model calculated the amount of } \\
\text { connected parking demands and supplies, } \\
\text { then subtracted it from the whole amount } \\
\text { of parking demand and supply. }\end{array}$ \\
\hline
\end{tabular}

\subsubsection{Technical requirements}

There are two different non-functional requirements: operational and technical. Some technical requirements were recognized based on the client environment and the existing software. Other technical requirements were recognized based on the project and extra programs needed to run the project. Table 3-2 shows these technical requirements. 
Table 3-2: Technical Requirement

\begin{tabular}{|l|l|}
\hline Technical Requirement & Solution \\
\hline Working with their work environment. & $\begin{array}{l}\text { The program was designed to work with } \\
\text { ArcInfo 9.3.1 } \\
\text {.Net framework ver 3.5 } \\
\text { SQL EXPRESS 2008 }\end{array}$ \\
\hline $\begin{array}{l}\text { The program needs to work in that } \\
\text { environment. }\end{array}$ & $\begin{array}{l}\text {.NET Framework 3.5 } \\
\text { Network Analyst extension }\end{array}$ \\
\hline $\begin{array}{l}\text { Connect parking demands to parking } \\
\text { supplies. }\end{array}$ & $\begin{array}{l}\text { Network Analyst was used to connect } \\
\text { parking demand to parking supplies. }\end{array}$ \\
\hline $\begin{array}{l}\text { Calculate unsatisfied parking demands } \\
\text { and supplies. }\end{array}$ & Used field calculator. \\
\hline
\end{tabular}

\subsubsection{Operational Requirements}

This is a custom program that helps the client make decisions based on data and network analysis. The quality of data and information should be controlled and checked. If the data contain errors, the program will not recognize them.

\subsection{System Design}

Based on the client's goals and system requirements, the framework for this project was established to calculate the unsatisfied parking demands and supplies using a parking modeling tool. The tool would dock in an ArcMap document (.mxd). The tool connects the user to the data and provides a customized interface that uses the ArcGIS functionality (See Figure 3-1). 


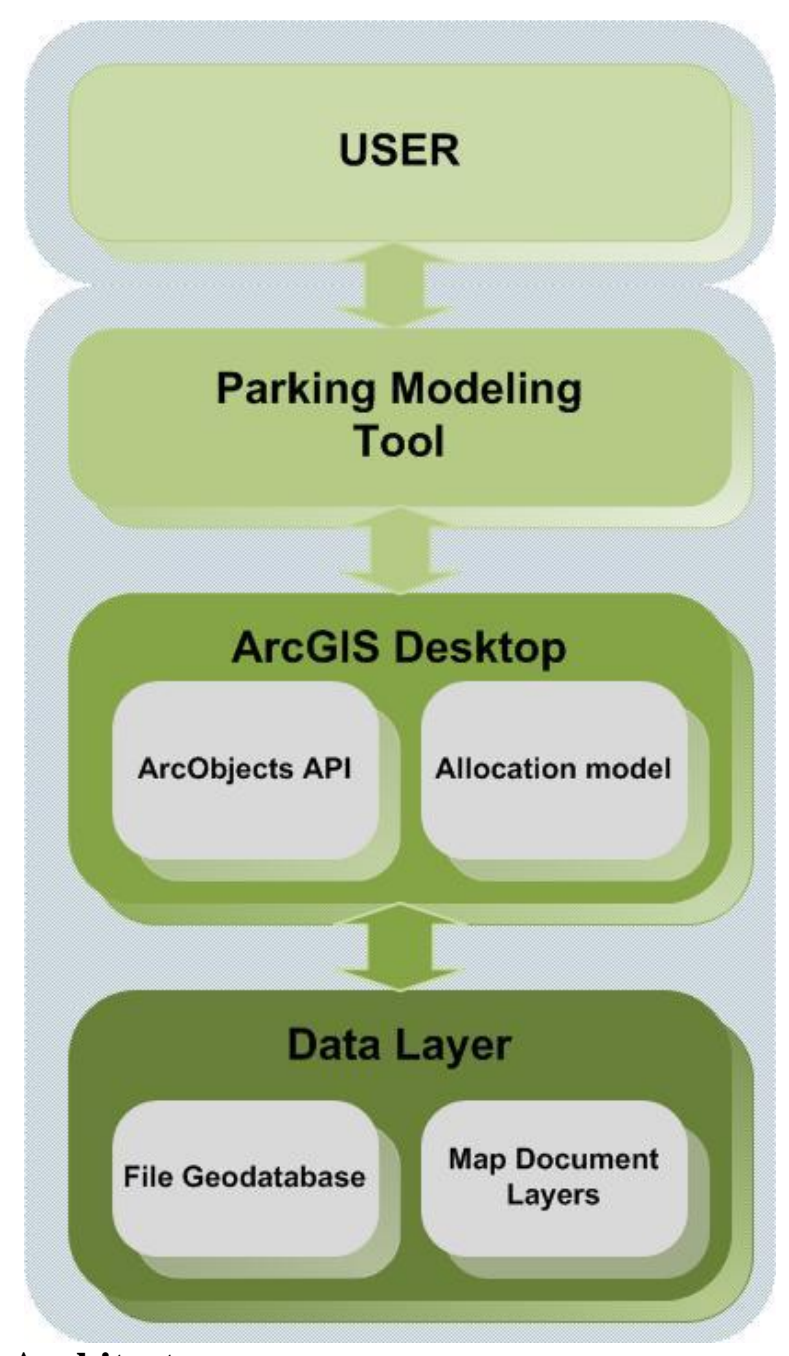

Figure 3-1: System Architecture

Data layers include file geodatabase and map document layers. SQL Server includes five tables for calculating parking demand. The file geodatabase contains three layers: the parking supply layer, the land use layer, and the network dataset. These layers provide a set of functionality within the system. The model retrieved the data inside the file geodatabase as a map layer inside ArcGIS. The client provided a file geodatabase that contains three layers and five tables in a spreadsheet format.

The ArcMap tool is the main part of the system. The tool connects the parking demand's tables that are stored in SQL Server to the file geodatabase. The file geodatabase will be accessible through presentation layers. The file geodatabase includes land use, parking supplies, and the network dataset. Users have the ability to try different scenarios and change parameters. After calculating parking demand, another application uses network analysis and the network dataset to connect parking demands and supplies. 


\subsection{Project Plan}

The project was started in February 2010 and concluded in December 2010. Initially, the project plans used a waterfall approach and the project plan consisted of two phases.

Figure 3-3 show all timelines and milestones of the project.

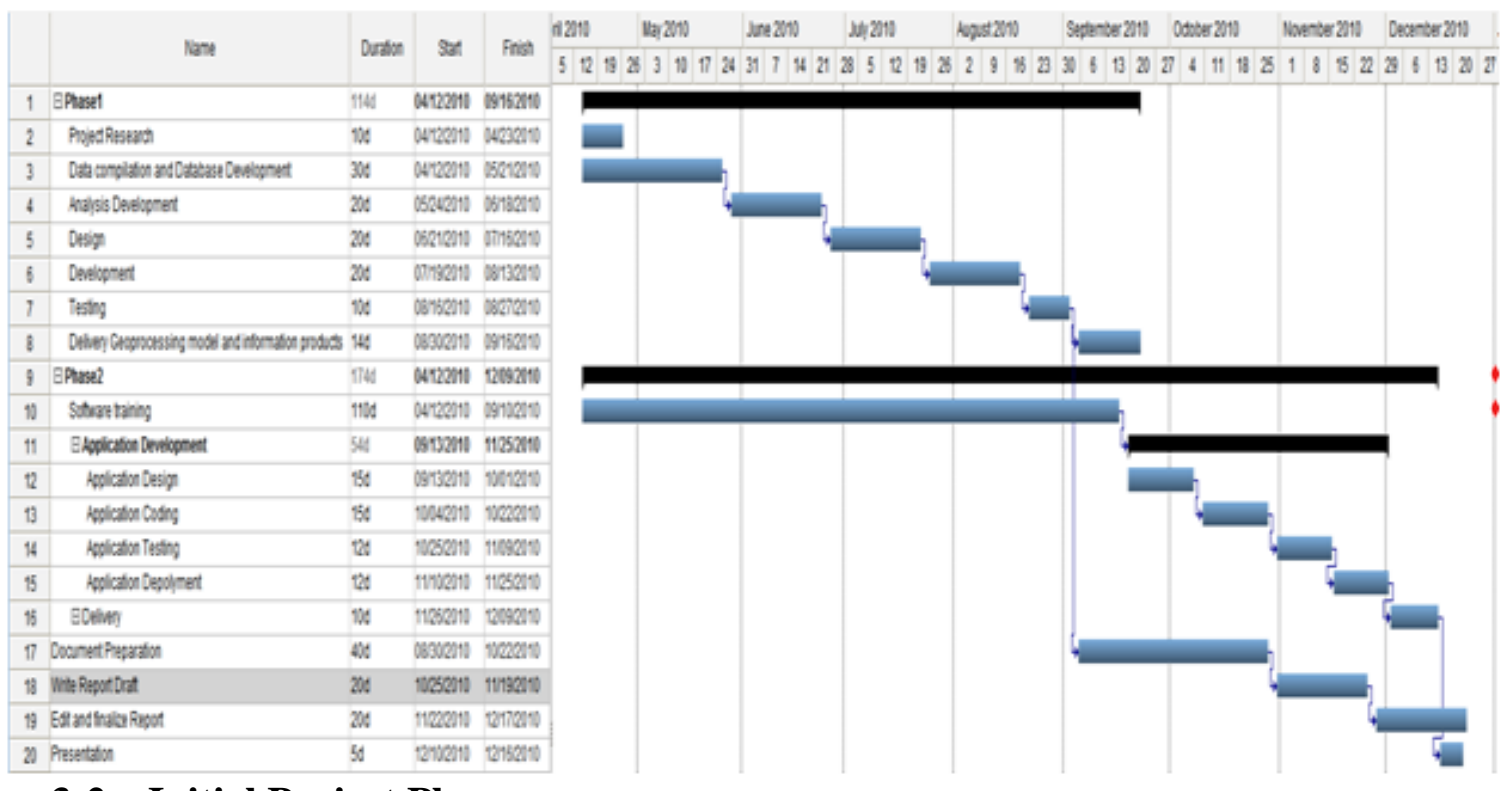

\section{Figure 3-2: Initial Project Plan}

The first phase of the project plan took a lot of time because the client changed the requirements in the middle of the project. First, the literature review was done, then the requirements, deliverables, risks, and timelines were specified. There were many changes to the timelines and phases because of the changing requirements, but the deliverables remained the same.

After changes, the project was organized into four phases: research and requirement, organization, analysis and implementation, and documentation.

\subsubsection{Research and Requirement analysis}

In the initial project plan, the research and requirement analysis was divided into separate phases that consisted of researching the problem, recognizing deliverables, and proposing a solution.

\subsubsection{Organization}

In this phase, the data were received and investigated. There was much communication between the client and project team. This part took a large amount of time because the client assumed that he had already sent some parts of the data but he had not. The expectations of the client were limited and written into the scope for the project. The organization phase included designing a database. 


\subsubsection{Analysis and Implementation}

The analysis phase took the longest time to complete. This time was dedicated to developing applications, finalizing geoprocessing procedures for the dataset preparation and model, and testing the applications.

\subsubsection{Documentation}

In Phase 4, the deliverables for the project, including the parking model, file geodatabase and user documentation, were recorded on a DVD. The user documentation included the comments written in the code for better understanding of the code for future use, the development process of the project, and detailed metadata.

\subsection{Summary}

The overall system design and project plan were discussed in this chapter. A requirements analysis was conducted to specify the goals of the project. Two requirements, functional and technical, were discussed. The discussions of the project plan described the required tasks with their proposed milestones and described the changes made to the task management process as the project progressed. 


\section{Chapter 4 - Database Design}

The client provided the data for this project in a file geodatabase and spreadsheet format. Analysis and data preparation were performed on the data to prepare the data for the functional requirements of the project. For the integrity of the data, the data in the spreadsheet format were transferred to the database. To meet this transformation, I first provided the conceptual model then the logical model. To prepare data for the project, the core of the file geodatabase was kept the same as before; however, some other data preparation was performed to better adjust the data to the model and calculations based on the client's need.

\subsection{Conceptual Data Model}

The conceptual data model describes the data and the attributes that were needed to ensure system functionality. As detailed in the functional requirements, the system needed to incorporate the parking demands table with the land use, the parking supplies, and the road network layers. There are two Unified Model Language (UML) diagrams, which define the relationship of entities inside the database.

Since the output of the parking demand model would be used for the parking model, first we designed the conceptual data model for parking demand (Figure 4-1). 


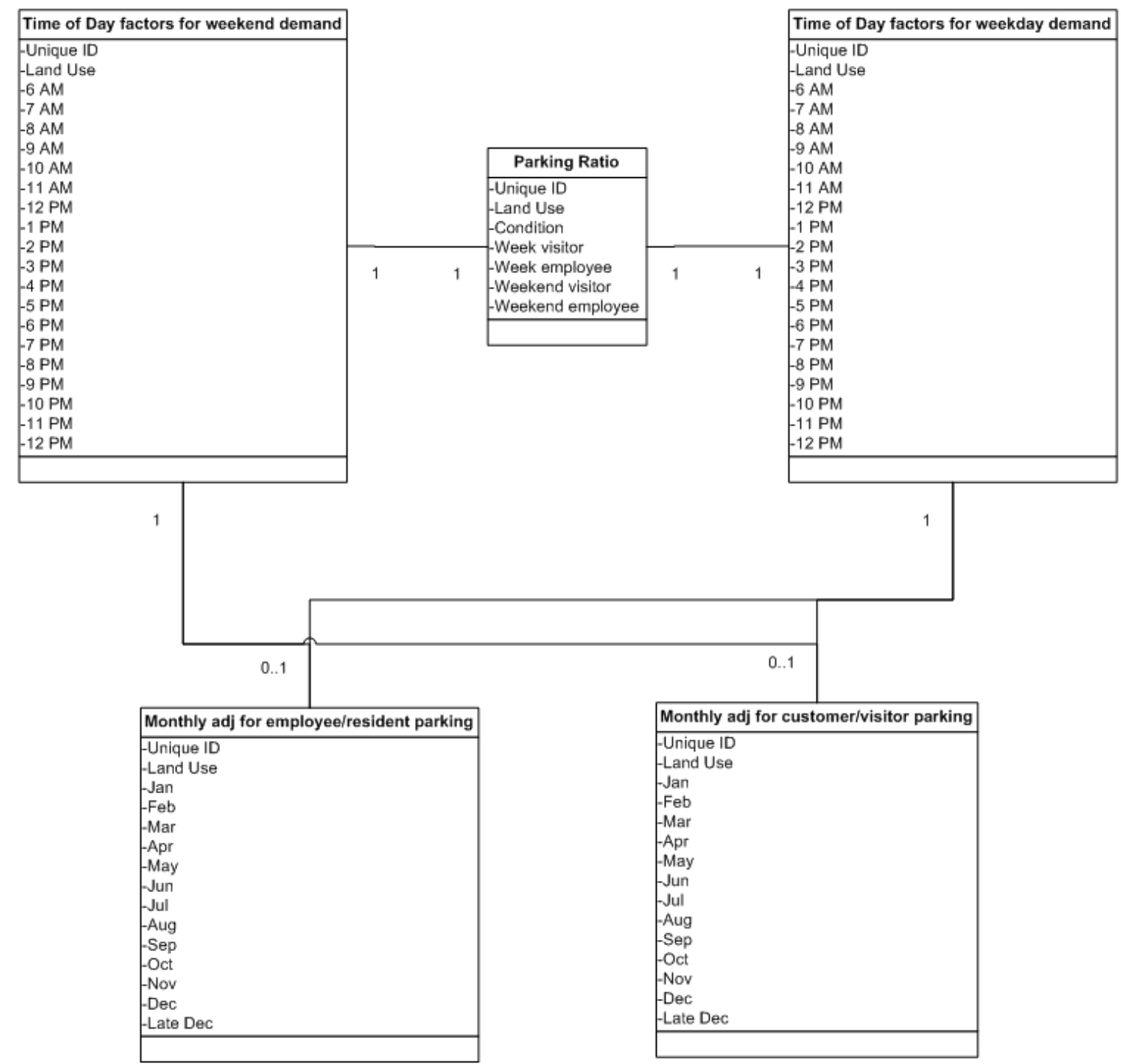

Figure 4-1: Parking demand conceptual data model

Figure 4-2 illustrates the relationship between parking demands, supplies, and roads. The relationship between parking demand and Road is many to one, and the association is parking demand near / adjacent to Road. The relationship between parking supplies and Road is many to one, and the association is parking supply near / on Road.

\begin{tabular}{|c|c|c|c|c|c|c|}
\hline \multirow{4}{*}{$\begin{array}{l}\text { Parcel land use } \\
\text {-Land Use } \\
\text {-Units } \\
\text {-Demand } \\
\text {-Unsatisfied Demand } \\
\text {-Unique ID }\end{array}$} & & & \multirow{4}{*}{\begin{tabular}{|l}
\multicolumn{1}{|c}{ Road } \\
-Unique ID \\
-Street Name \\
-Route Class \\
-Speed (MPH) \\
-Miles
\end{tabular}} & & & \multirow[b]{2}{*}{ Parking Supplies } \\
\hline & & & & & & \\
\hline & & & & & & -Unique ID \\
\hline & $0 .{ }^{*}$ & 0.1 & & 0.1 & $0 . .^{*}$ & -Unsatidfied Supplies \\
\hline
\end{tabular}

Figure 4.2: File geodatabase conceptual data model 


\subsection{Logical Data Model}

Once the conceptual model was established, the logical data model was developed. The client provided the geodatabase and tables for the project.

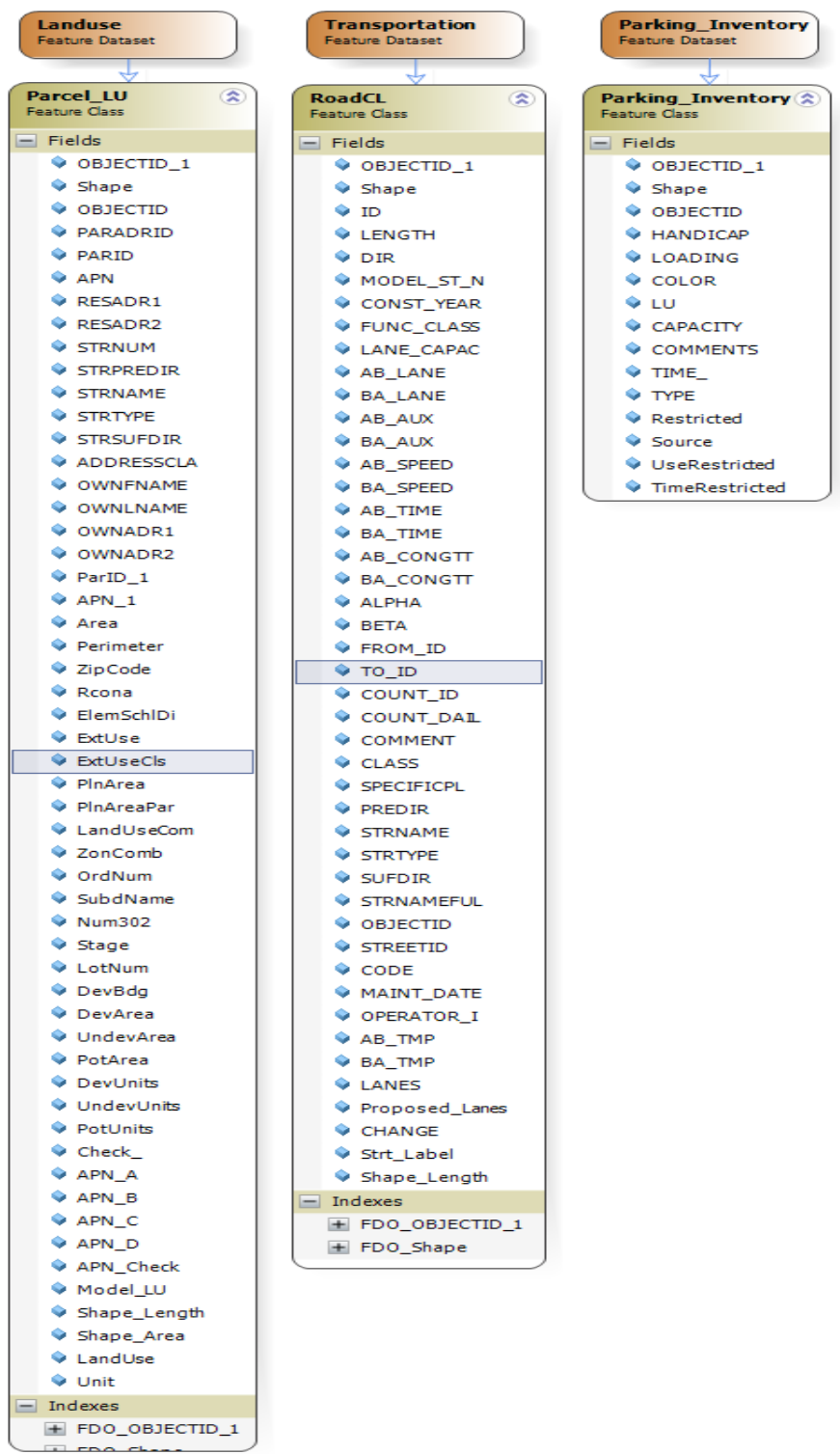

\section{Figure 4-3: Geodatabase logical data model}

Figure 4-3 shows the geodatabase logical model. The geodatabase included three feature classes representing Landuse, Parking_Inventory, and Transportation. In order to work with the model, two new fields were added to the Landuse feature class, which were Land Use and Unit, and a field was added to road network, which was Cost. Two new fields were created to store the results inside the Landuse and Parking_Inventory feature classes, and were named unsatisfied parking demand and supplies. 


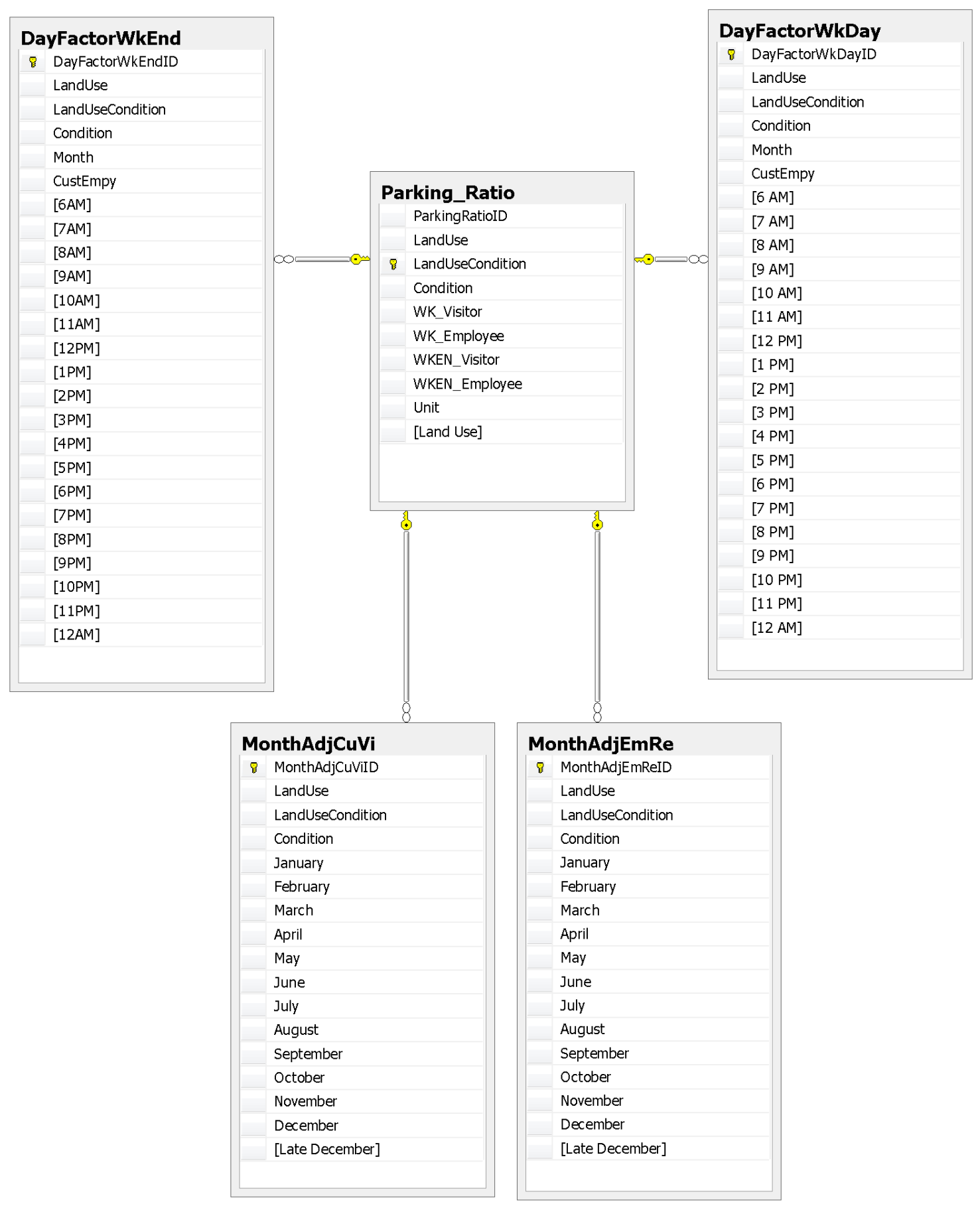

Figure 4-4: Parking demand logical model

Figure 4-4 shows the parking demand logical model. There were five tables that represented Parking_Ratio (parking ratio), MonthAdjCuVi (monthly adjustment for customer/visitor parking), MonthAdjEmRe (monthly adjustment for employee/resident 
parking), DayFactorWkDay (time of day factors for weekday demand), and DayFactorWkEnd (time of day factors for weekend demand). Five tables provided information about parking demand calculation. They are stored inside SQL Express.

\subsection{Data Sources}

The client provided all data for the project. The data were provided as a file geodatabase in the NAD_1983_StatePlane_California_II_FIPS_0402_Feet projection, and as Excel tables.

\subsection{Data Scrubbing and Loading}

Data for the project were modified to ensure data connectivity between tables. Some new fields were created and their values were calculated to integrate data and prepare them for the model. There was some modifications to the tables to transfer them from Excel to the file geodatabase.

\subsubsection{Landuse feature class}

Two fields were added to the Landuse feature class: LandUse and Unit. The values of the land use were the same as the values of landusecondition inside the parking ratio table, and the value was considered based on another field, which was an ExtUse. The ExtUse field contained the land use for each parcel. The Unit field inside the Landuse feature class was calculated using four fields: DevUnits, UndevUnits, DevArea, and UndevAreas. The DevUnits field contained the value of developed units for residential land use. The DevArea field contained the value of developed area for shopping center land use and office land use. The UndevUnits and the UndevAreas field were contained the value of undeveloped units and area.

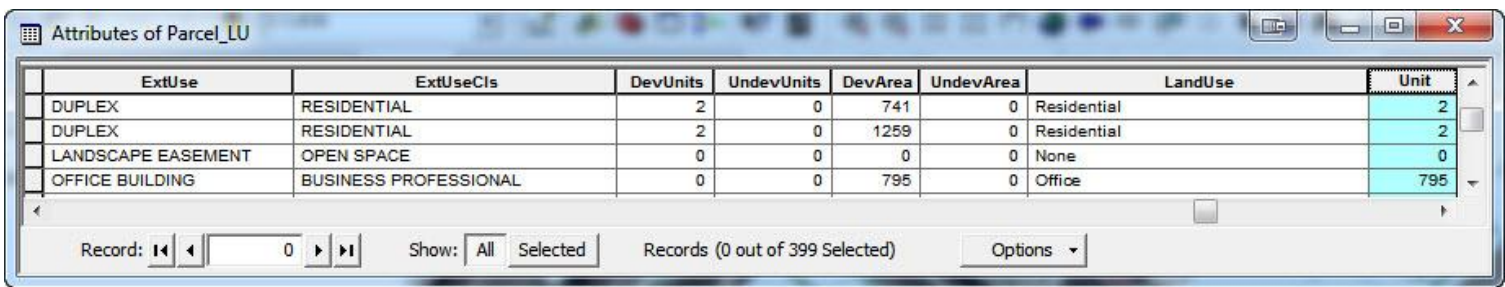

\section{Figure 4-5: Parcel land use feature class}

\subsubsection{Parking_Inventory feature class}

The Parking_Inventory feature class contained all parking spaces (public and private). Some of the parking supplies were inside the residential area or belonged to car dealerships. These parking supplies were edited and a value of zero was assigned to their capacity. 


\subsubsection{Road network}

For the road network, a new field was created, called minutes, with a field type of double. The value inside the minutes is the walking time and it was calculated using this formula: ( ( [Miles] / [Speed_MPH] $) * 60$ ) Speed_MPH for walking is 1.9 (miles / hr).

\subsubsection{Parking demand tables}

The parking demand tables were stored in an Excel worksheet containing five tables. The client used these tables to calculate parking demand. The client's process of calculating parking demand was to look at the land use for each parcel, as well as its definition provided by the specific city or county since they were not always consistent. Previously, the client would manually consult the tables to determine the parking demand. In this project, two new fields -- LandUseCondition and Condition -- were added to each table. The LandUseCondition field was a primary key for creating a relationship between the tables. The Condition field is a free text field to hold any user comments. Two fields Month and CustEmpy -- were added to two of the tables, Day Factor Weekend and Weekday, to standardize the contents of the fields. The Month field contained three values: December, LateDecember, and None. The CustEmpy field contained two values: Customer and Employee.

\subsection{Summary}

This chapter focused on the design of the database used for this project. The conceptual model was used to identify the feature, the attribute, and the relationship between them. The logical data model looked at the physical design of both the database and the geodatabase. The different sources for the project were discussed. Finally, the data scrubbing and loading section described how the group prepared the data for the database and the geodatabase. 


\section{Chapter 5 - Implementation}

This chapter details the two phases of the project: the parking demand phase and the location-allocation phase.

\subsection{Parking Demand}

One of the main goals of the project was to integrate the client's parking demand model inside the ArcGIS environment with a user friendly interface that provides the user with the ability to add, cut, or edit the information inside and outside of the ArcGIS environment. At the beginning of the project, the client provided a tool with VBA code for calculating parking demand, and the client requested that the code be rewritten in Python. In the middle of the project, the client provided five parking demand tables and requested that they be used instead. This caused a delay in the implementation of this phase of the project.

\subsubsection{Implementation of SQL Express}

The client provided the parking demand tables in a spreadsheet format for this project. One of the requirements of the project was that the tables were accessible and editable inside and outside of the ArcGIS environment. SQL Server was selected for the project to store tables because we can access and edit tables inside the SQL Server from ArcGIS environment using .NET environment, and the tables are editable outside of ArcGIS environment as well. There are several versions of SQL Server and for this project, SQL Express was chosen because it is free.

First, I standardized the data within the spreadsheet. I added new columns and lines to the tables to contain the standardized values. Second, I made an empty database inside of SQL Express and I imported all the spreadsheets to the database using Microsoft SQL Server 2008 > Import and Export Data (32 bit).

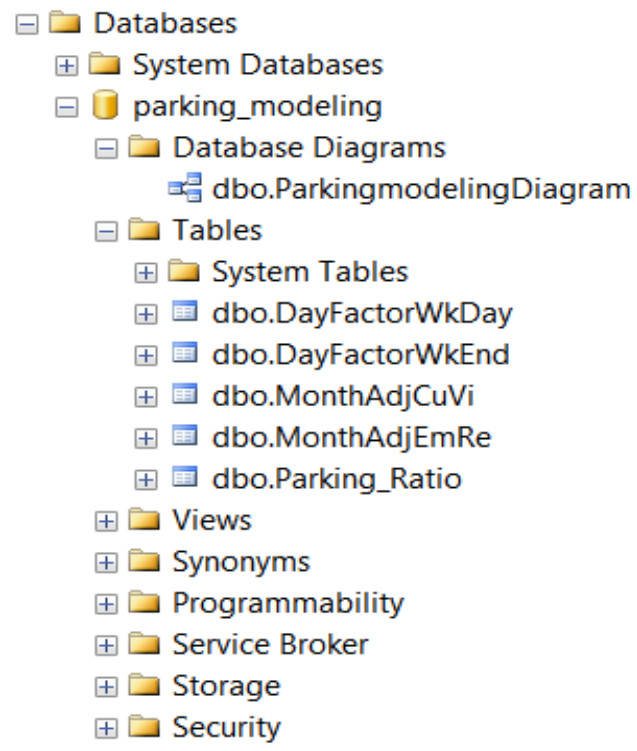

Figure 5-1: SQL Express directory 
Figure 5-1 shows the database and tables and a database diagram. For making the relationship between the tables, a field, which was landusecondition, from the parking ratio table was selected as a primary key. Then I ran an SQL query to make sure all the values of foreign keys inside the other four tables were the same as the primay key.

SELECT * FROM < foreign_key_table> WHERE < foreign_key_column> NOT IN (SELECT < primary_key_column) FROM < primary_key_table>).

For creating the relationship in the SQL Express environment, a new database diagram was created, then all the tables that had a relationship to one another were added to the database diagram and we dragged and dropped from the foreign key to the primary key to create a relationship.

\subsubsection{Parking demand application}

One of the requirements of the project was building a friendly interface that provides the ability for the client to change parameters. There were two ways to develop the user interface inside the ArcGIS environment that provided the ability for the user to make changes in the variables. these two ways were VBA and .NET. The .NET environment was chosen for developing the interface because it was more convenient to work with SQL Server. C\# was used as a programming language for the Parking Demand application. The application contains four general steps. An outline of the procedure is provided in Figure 5-2.

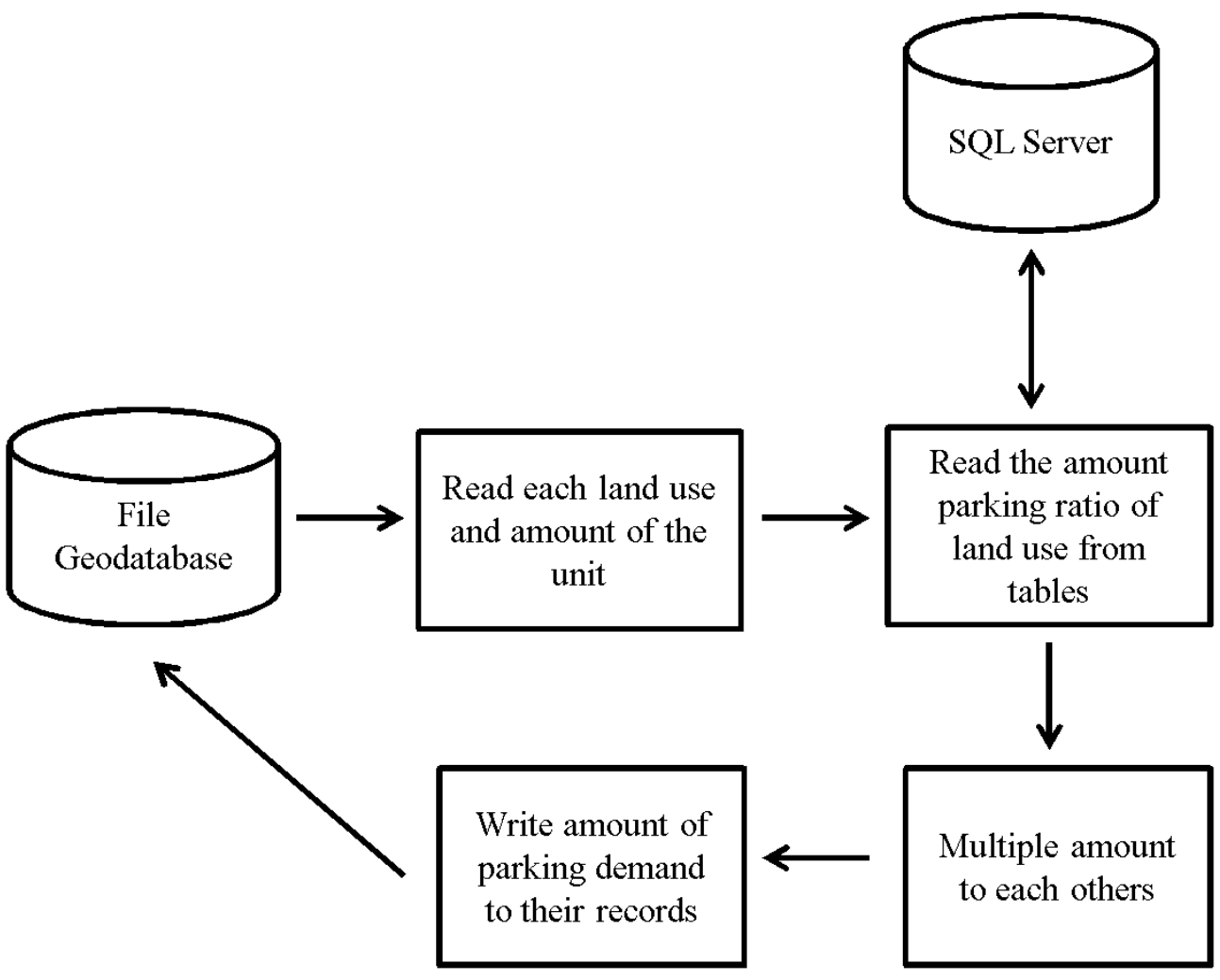

Figure 5-2: Parking demand method 
In the first step, the application uses the cursor method and reads line by line from the feature class and it returns the value of land use and unit fields that were specified by the user. Some land uses do not have parking demands like parks and open spaces, so their land use is None. If the value is None, the application skips the next two steps and goes to last step, and it stores the value of zero in the demand field.

In the second step, the application uses ADO.NET to connect to SQL Server and to read data from tables. In ADO.NET, the program opens the connection to SQL Server, and then defines a SQL command, then executes the command. It is important to check the condition; if no value is returned, it returned the default value, which is zero.

Table 5-1: Query syntax from SQL Server

\begin{tabular}{|c|c|c|}
\hline Variable & Table & SQL Query \\
\hline Parking Ratio & Parking Ratio & $\begin{array}{l}\text { "SELECT [" + nameoffield + "] FROM } \\
\text { [dbo].[Parking_Ratio] WHERE } \\
\text { [LandUseCondition] = "' + landusecondition + } \\
\text { "'"; }\end{array}$ \\
\hline MonthlyAdjCuVi & $\begin{array}{l}\text { Monthly } \\
\text { adjustment for } \\
\text { customer/visitor } \\
\text { parking }\end{array}$ & $\begin{array}{l}\text { "SELECT [" + timeofmonth + "] FROM } \\
\text { [dbo].[" + tableformonthlyadjustment + "] } \\
\text { WHERE [LanduseCondition] = "' + } \\
\text { landusecondition + "'"; }\end{array}$ \\
\hline MonthlyAdjEmRe & $\begin{array}{l}\text { monthly } \\
\text { adjustment for } \\
\text { employee/resident } \\
\text { parking }\end{array}$ & $\begin{array}{l}\text { "SELECT [" + timeofmonth + "] FROM } \\
\text { [dbo].[" + tableformonthlyadjustment + "] } \\
\text { WHERE [LanduseCondition] = "' + } \\
\text { landusecondition + "'"; }\end{array}$ \\
\hline FactorWeekDay & $\begin{array}{l}\text { Time-of-Day } \\
\text { Factors for Week } \\
\text { Day Demand }\end{array}$ & $\begin{array}{l}\text { "SELECT [" + timeofday + "] FROM [dbo].[" + } \\
\text { tableofdayfactor + "] WHERE } \\
\text { [LanduseCondition] = "' + landusecondition + "' } \\
\text { AND [Month] = 'Late December' AND } \\
\text { [CustEmpy] = "' + CustEmpy + "'"; }\end{array}$ \\
\hline FactorWeekEnd & $\begin{array}{l}\text { Time-of-Day } \\
\text { Factors for } \\
\text { Weekend } \\
\text { Demand }\end{array}$ & $\begin{array}{l}\text { "SELECT [" + timeofday + "] FROM [dbo].[" + } \\
\text { tableofdayfactor + "] WHERE } \\
\text { [LanduseCondition] = '" + landusecondition + "' } \\
\text { AND [Month] = 'Late December' AND } \\
\text { [CustEmpy] = '" + CustEmpy + "'"; }\end{array}$ \\
\hline
\end{tabular}


Table 5-1 shows the syntax of SQL query for retrieving data from SQL Server.

In the third step, we calculate the amount of parking demand. In Figure 5-3, the orange represents the input variables and the green represents the output value.

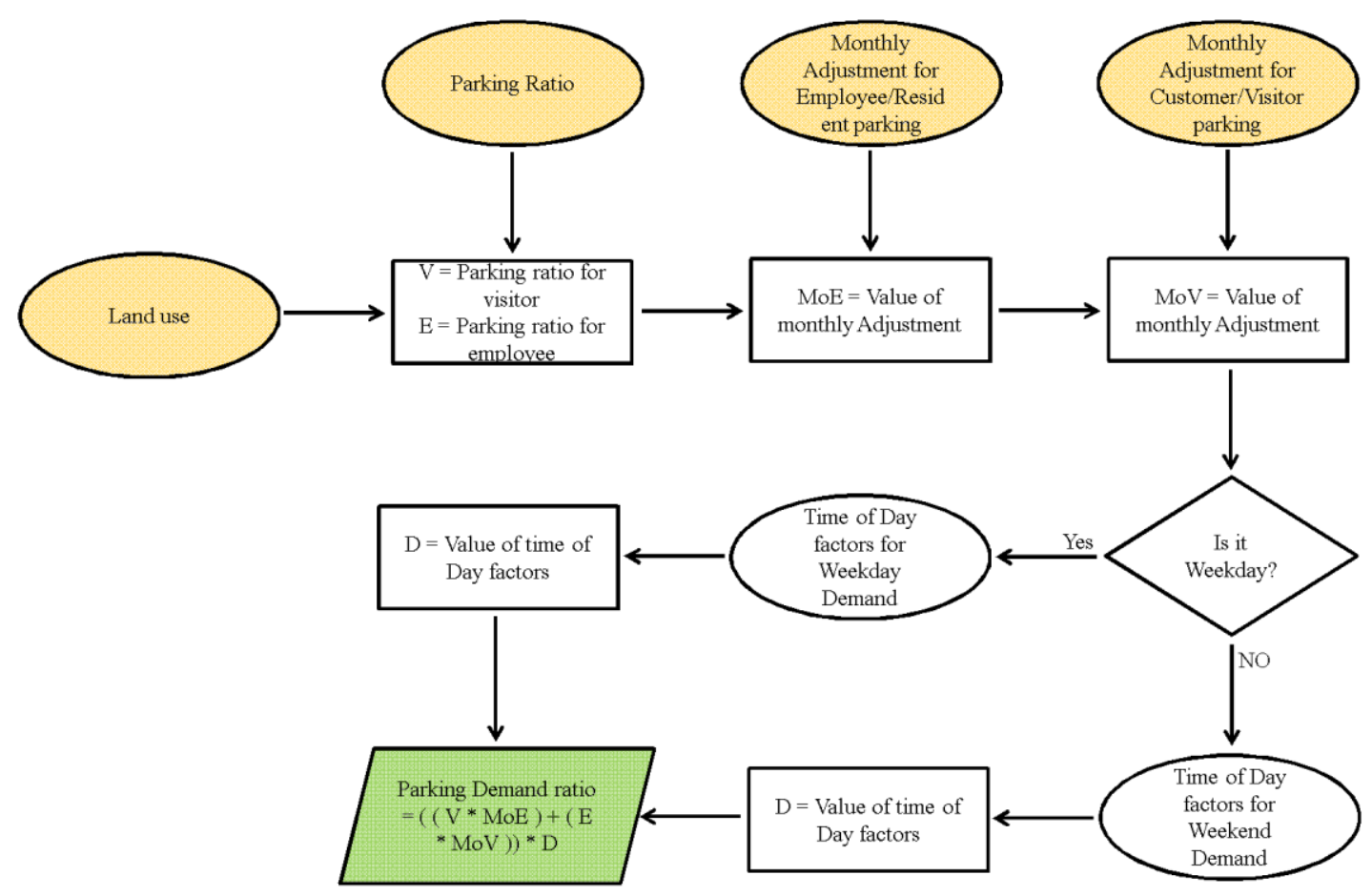

Figure 5-3: Parking demand flowchart

In the fourth step, the application creates a new field with the name specified by the user and records the amount of parking demand in the field. It then moves to the next row until it reaches the last feature.

\subsubsection{Parking demand interface}

After installing the application and importing the tool as a customized application and then running the tool, a new window will be open. Figure 5-4 shows the parking demand interface. 


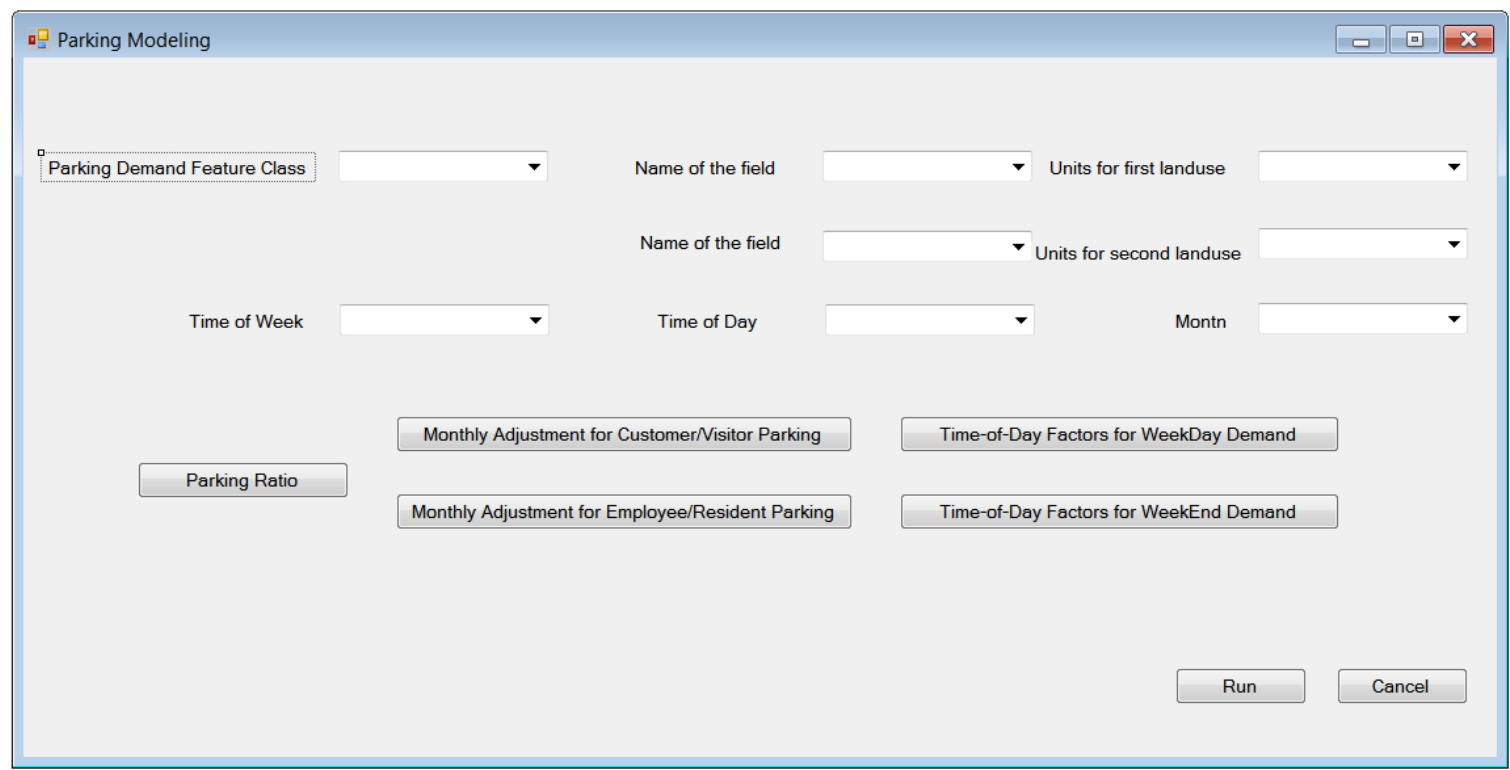

\section{Figure 5-4: Parking demand interface}

In the first step, the user chooses the land use feature class from a combo box that lists the feature classes and layers inside the mxd document.

After the user selects the land use feature class, the second and third combo boxes become active. In the second combo box, Name of the field, the user can select the field that represents land use. In the third combo box, Units for first land use, the user can select the field that represents units of land use. For example, units for a theater is the number of chairs, units for a school is the number of students, and units for shopping center is ksf ( $1 \mathrm{ksf}=1000$ square feet). In some situations, a parcel has two land uses. For example, some parcels' land use are both residential and hotel, so their units are different. The user has the ability to select another combination of land use and units in this situation.

There is a combo box for time of week from which the user can choose either weekday or weekend.

There is another combo box for time of day, which is from 6 am until 12 am, in onehour intervals.

The other part of the interface includes five buttons for accessing tables from the main interface. The first button is parking ratio.

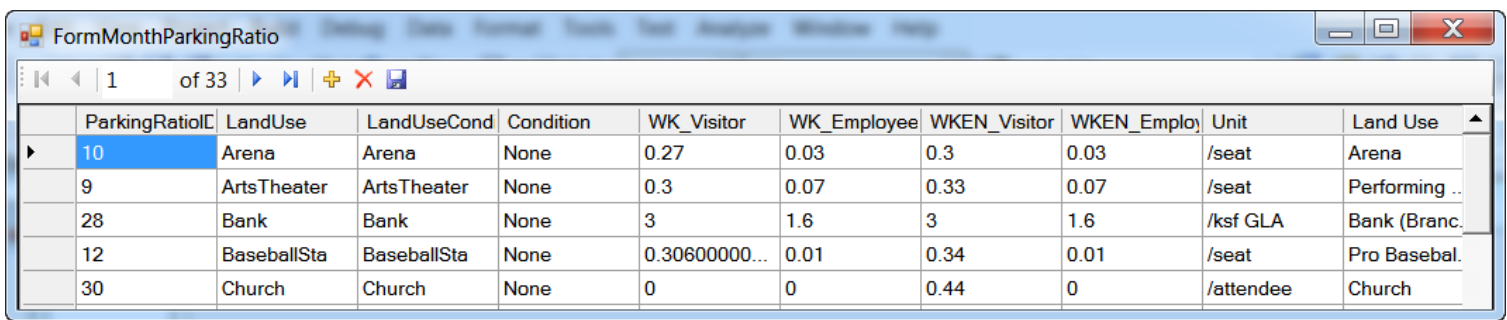

Figure 5-5: Parking ratio interface 
After clicking on the parking ratio button the window will be open. Figure 5-5 shows the parking ratio window. In this new window, the user is seeing the parking ratio table in the grid view. The user can edit and save values. The parking ratio table is the main table so if the user wants to add any new land use, they need to add it here. After the user adds the new land use, the land use will be added to the other four tables with default values and later the user can edit their values. The other four buttons are the same as the parking ratio button. After clicking the button, a new window will open.

\subsection{Location - Allocation}

After calculating parking demands, the second phase of the project is connecting each parking demand to a parking supply within a time threshold, and after that, calculating the amount of unsatisfied parking demands and supplies. Connecting supplies to demands using Network Analyst is a classic problem in transportation, and they use the phrase location - allocation problem for it. There are several methods to solve the locationallocation problem. In this project, random connection method was used to assign each parking supply to each parking demand. This tool was developed using Python script. A toolbox was created and Python script was stored as part of the toolbox. Figure 5-6 shows the toolbox; the code of the script is in the Appendix.

\section{Parking Modeling Parking Modeling}

Figure 5-6: Parking modeling toolset

\subsubsection{Location - Allocation application}

A Python script was written for the location-allocation problem. The advantage of using Python is that it is embedded within ArcGIS, and after writing the program, it is easy to provide an interface for the script and customize the interface. The custom toolbar was designed to include an interface, a layer, and Python code. 


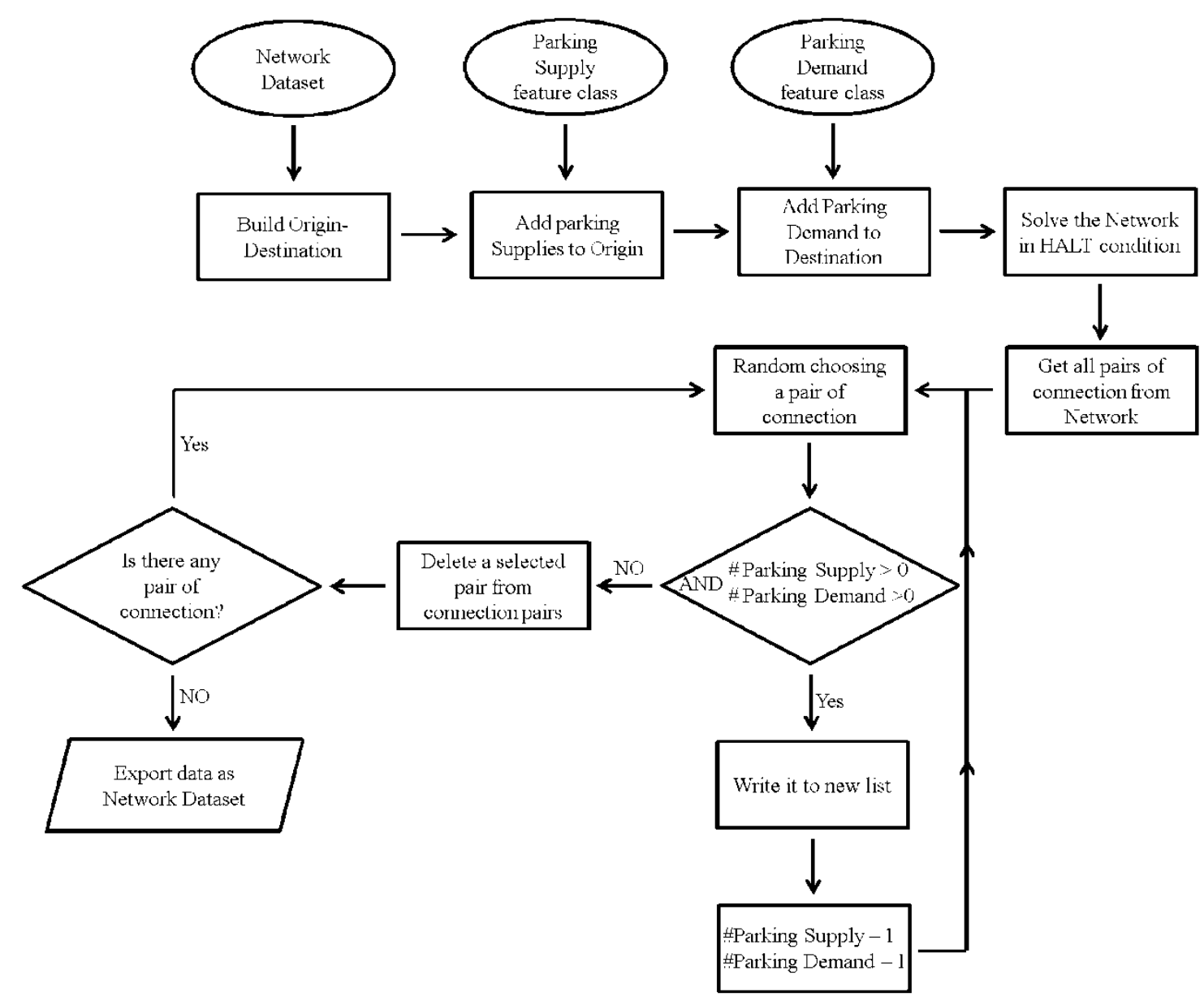

\section{Figure 5-7: Location - Allocation method}

Figure 5-7 shows the method I used for solving the location-allocation problem. In the first step of the process, the model makes a new OD matrix and we import parking supplies as an origin and parking demand as a destination. Then, the program solves the OD matrix. The output network contains a layer, named lines, that contains all connections of supplies and demands within a specified time threshold. The tool performs a random selection inside the line layer, then stores all lines in, and selects randomly from, the connections. Then the tool stores all lines in the network dataset, and it calculates unsatisfied parking supplies and demands and stores them in the origin and destinations layers inside the network dataset.

\subsubsection{Location - Allocation interface}

After adding a parking modeling toolbox to the ArcToolbox and running the parking modeling script a window will open. Figure 5-8 shows the parking modeling interface. 


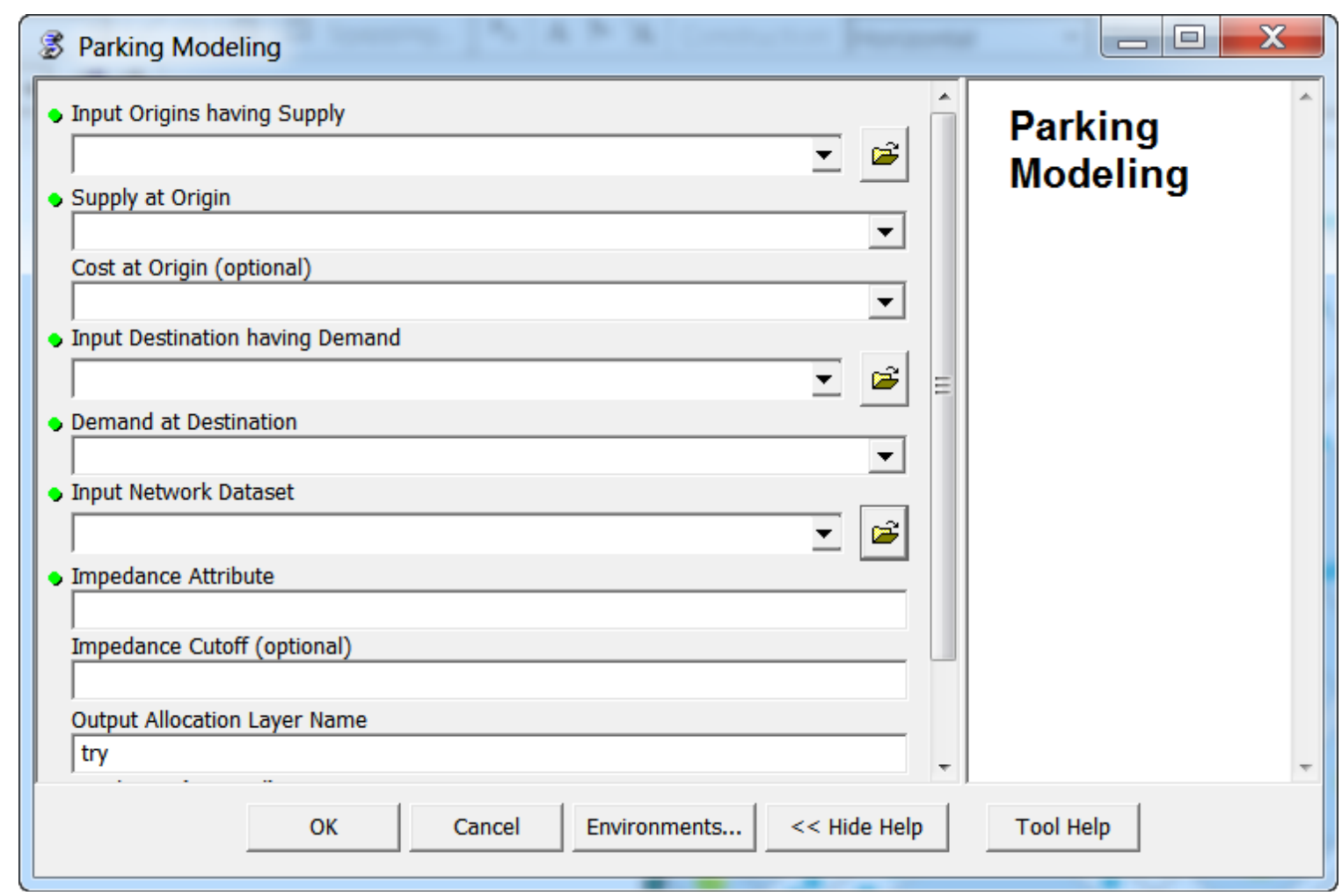

Figure 5-8: Location- Allocation interface

First, the user chooses the feature class that contains parking supplies. The combo box, Input Origins having Supply, shows the name of the point feature classes.

In the second combo box, Supply at Origin, the user chooses the field that stores the capacity of parking. In the fourth combo box, Input Destination having Demand, the user chooses the parking demand feature class, which is a land use feature class that contains a parking demand value for each parcel. Our Input Destination can be a point or polygon feature class. If the input is a polygon feature class, the program converts the polygon feature class to a point feature class using the feature to point tool. In the sixth combo box, Demand at Destination, the user chooses a field that stores the amount of parking demands.

\subsection{Summary}

This chapter provided a detailed discussion of the two tools that were developed and the method used for the implementation of the project. It contained two major sections: the customized application for calculating parking demand, and the implementation of SQL Server. In this section, we also looked at the method and functionality provided for the user. Furthermore, the scripting tool used calculated unsatisfied parking demands and supplies using Network Analyst. 


\section{Chapter 6 - Results and Analysis}

This chapter focuses on the analysis results using the parking demand add-in and location-allocation tools. The first section discusses how to add GIS tools to the desktop. The second section discusses the results of the parking demand tool, which was implemented using C\# and ADO.NET. The third section discusses the location-allocation tool, which was developed using Python, and the result of that tool.

\subsection{GIS Tools Installation and Results}

The two GIS tools were developed using Python and C\# and ESRI ArcGIS 9.3.1 packages with an ArcInfo-level license. These tools require the Network Analyst extension to be present.

Within an ArcMap session, open the customize window. Add Parkingdemand.dll to commands using the Add from file button. Then select PARKING from categories and add the PARKING command to the toolbar (Figure 6-1).
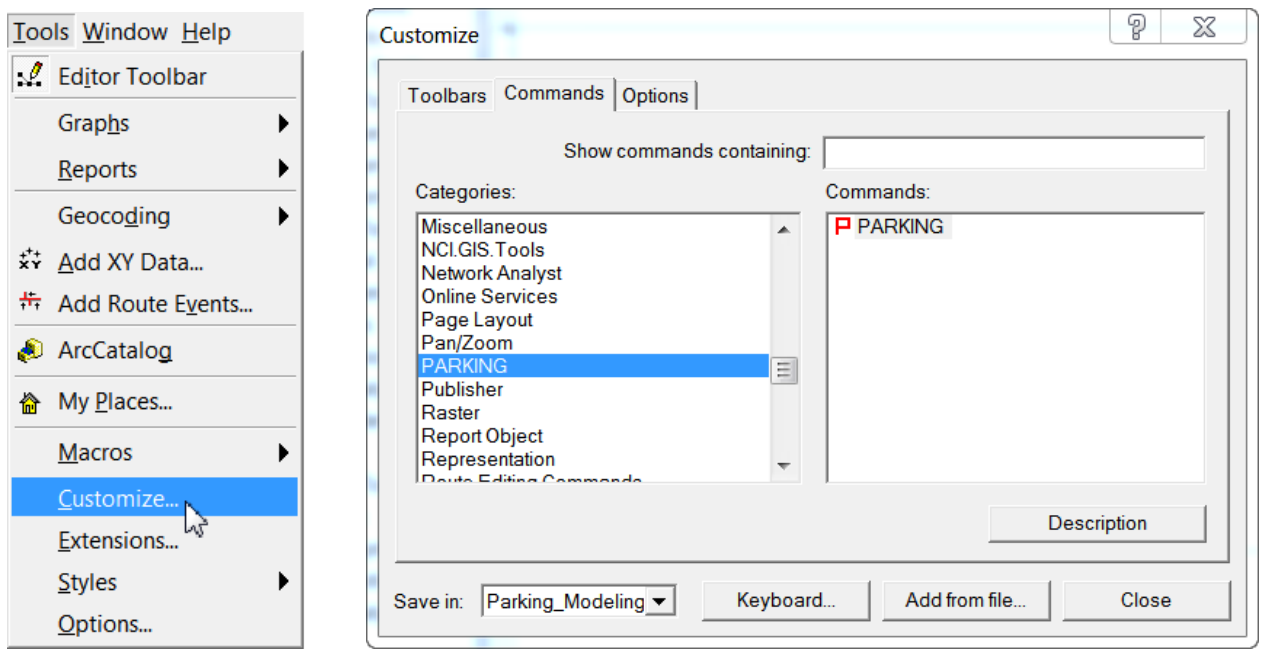

Figure 6-1: Adding the parking demand tool

Within an ArcMap or ArcCatalog session, open the ArcToolbox window. Add the location-allocation tool to the toolbox using Add Toolbox (Figure 6-2). 

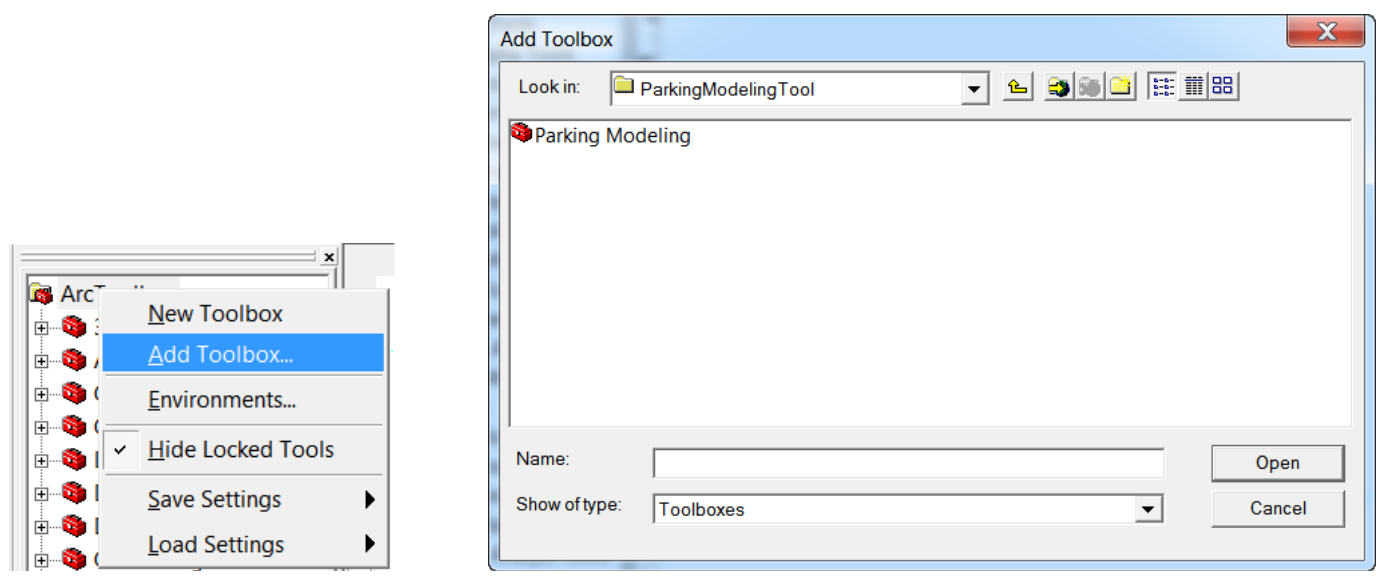

Figure 6-2: Adding the Location-Allocation tool

\subsection{Parking Demand Results}

The parking demand tool can run with different parameters. Figure 6-2 shows the input that was chosen to execute the tool. 


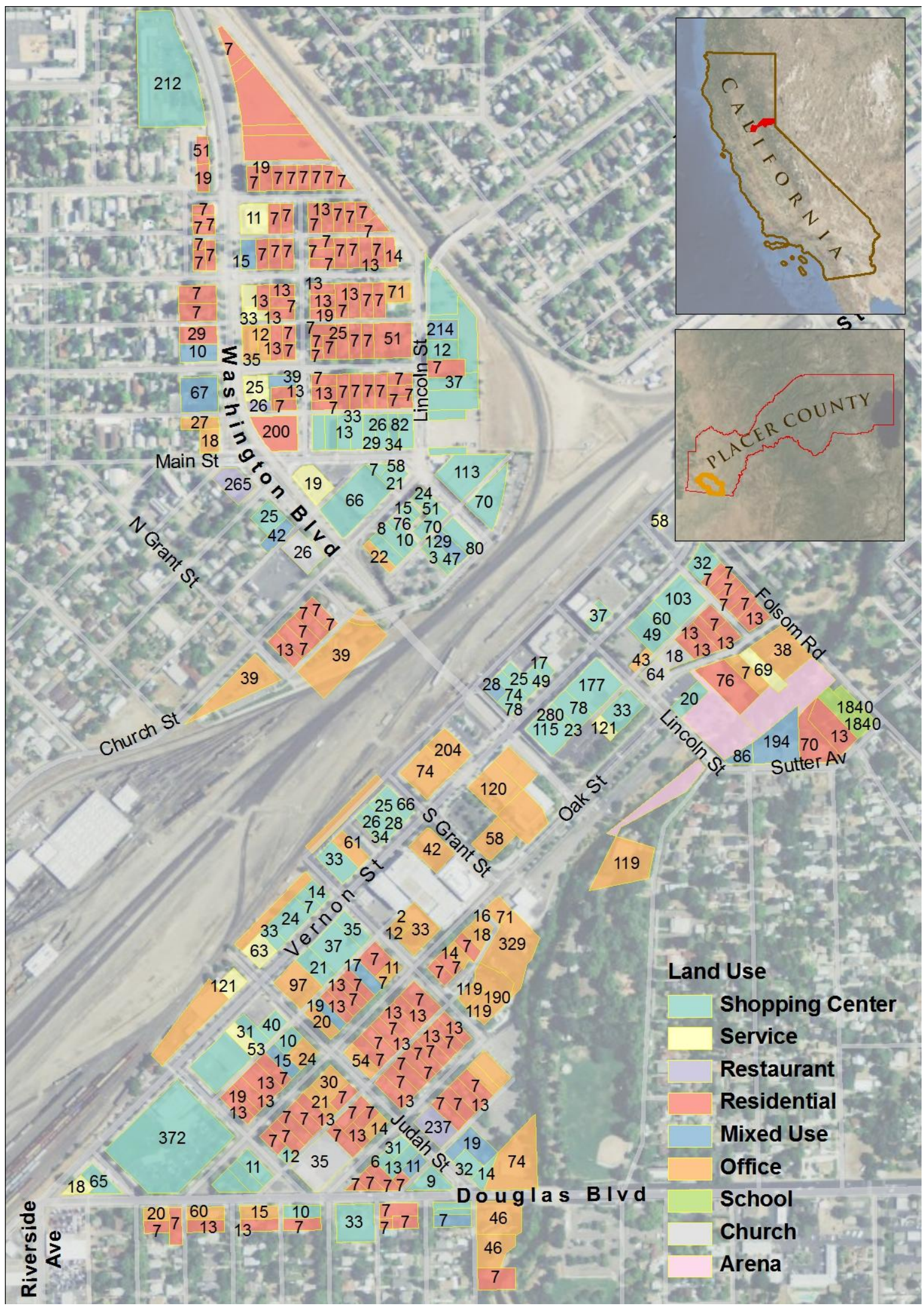

Figure 6-3: The result of parking demand tool at 8 PM in January 


\subsection{Location-Allocation Results}

The location-allocation tool is dependent on the network and the time threshold to produce the network dataset that contains the origins, destinations, and lines (Figure 6-4).

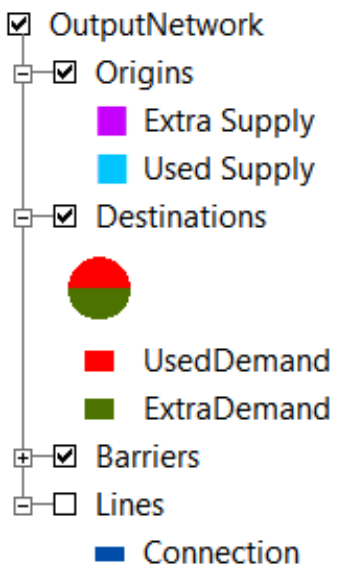

Figure 6-4: Location-Allocation network dataset output

Figure 6-5 shows the result of location-allocation tool. 


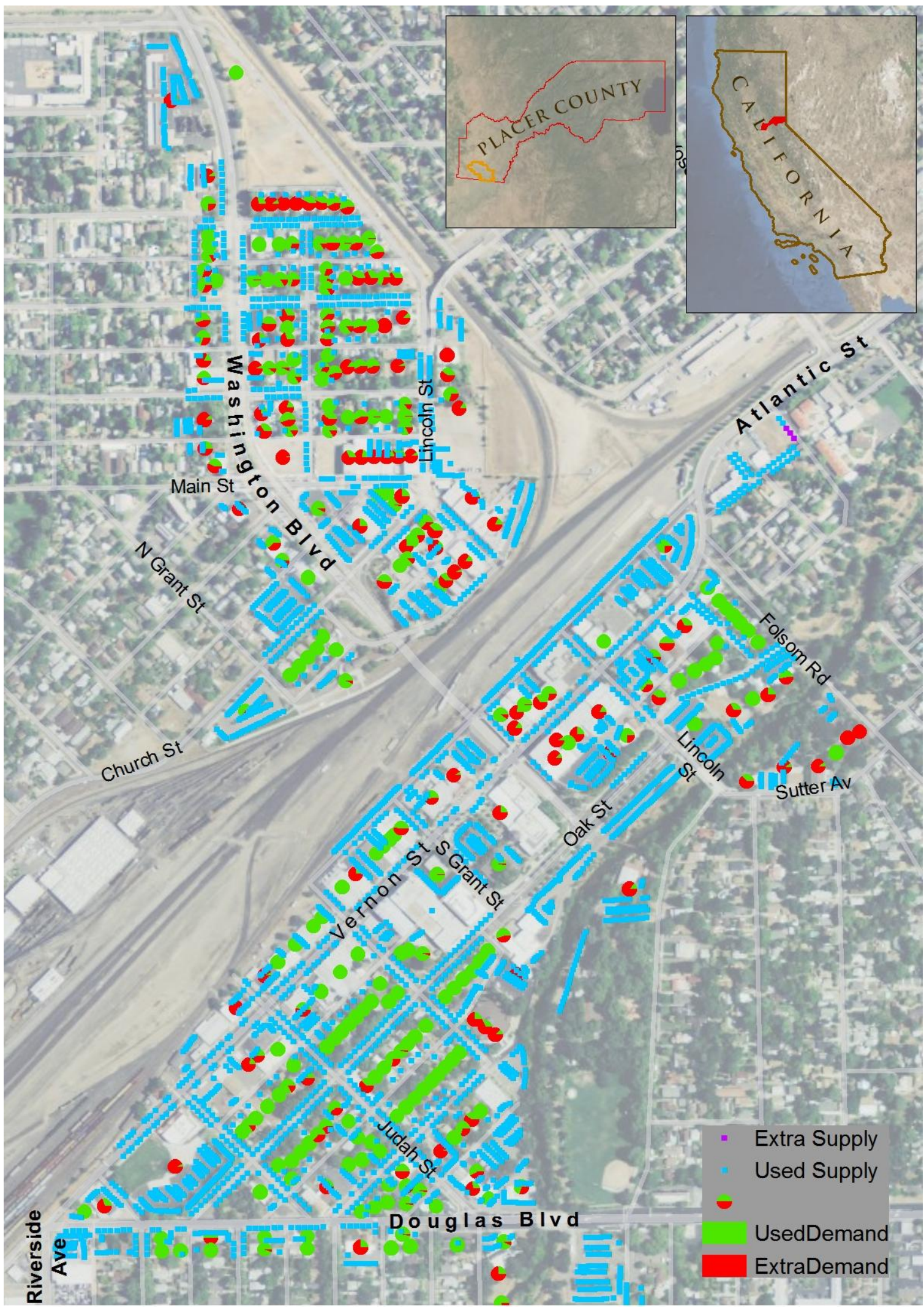

Figure 6-5: Result of Location-Allocation tool within 5 minute 
The origin layer's table contains all origins. The table contains fields that show the amount of supply, and the amount of extra and used supply for each supply (Figure 6-6).

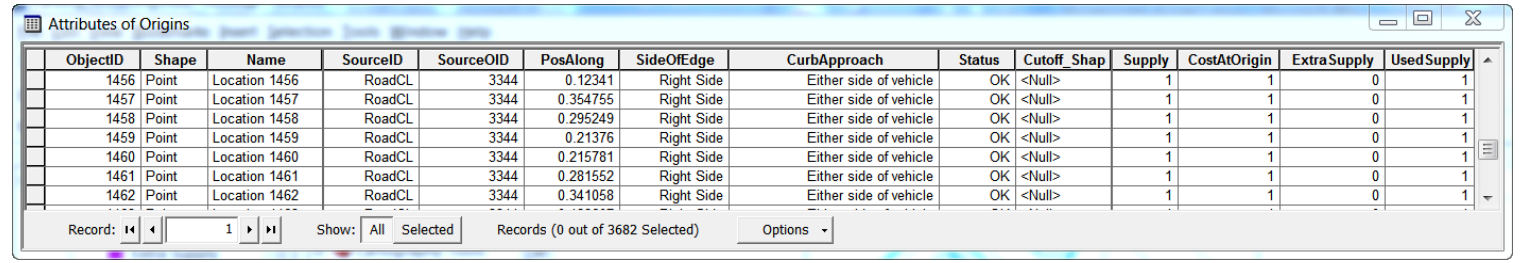

Figure 6-6: Origin layer table

The destination layer's table contains all destinations. The table contains fields that show the amount of demand, and the amount of unsatisfied and satisfied demand for each demand (Figure 6-7).

\begin{tabular}{|c|c|c|c|c|c|c|c|c|c|c|c|c|c|}
\hline \multicolumn{12}{|c|}{ 圃 Attributes of Destinations } & \multicolumn{2}{|l|}{\begin{tabular}{|l|l|l|l|l|l|l|l}
0 & 回 \\
\end{tabular}} \\
\hline & ObjectlD & Shape & Name & SourcelD & SourceOID & PosAlong & SideOfEdge & CurbApproach & Status & Demand & ExtraDemand & UsedDemand & \\
\hline 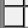 & 4 & Point & Location 4 & RoadCL & 3303 & 0.58211 & Left Side & Either side of vehicle & $\mathrm{OK}$ & 198 & 180 & 18 & $\equiv$ \\
\hline 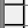 & 5 & Point & Location 5 & RoadCL & 3303 & 0.294646 & Left Side & Either side of vehicle & OK & 198 & 187 & 11 & \\
\hline & 6 & Point & Location 6 & RoadCL & 3328 & 0.236593 & Left Side & Either side of vehicle & OK & 0 & 0 & 0 & \\
\hline 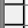 & 7 & Point & Location 7 & RoadCL & 3410 & 0.770411 & Right Side & Either side of vehicle & OK & 37.2 & 28.2 & 9 & \\
\hline 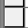 & 8 & Point & Location 8 & RoadCL & 3328 & 0.096324 & Left Side & Either side of vehicle & OK & 0 & 0 & 0 & \\
\hline & 9 & Point & Location 9 & RoadCL & 3410 & 0.324419 & Right Side & Either side of vehicle & OK & 13.95 & 1.95 & 12 & \\
\hline & 10 & Point & Location 10 & RoadCL & 3337 & 0.277218 & Left Side & Either side of vehicle & OK & 3.85 & 1.85 & & \\
\hline & 11 & Pnint & I nration 11 & Rnadlil & 3337 & ก $4 \cap 2917$ & I Aft Sirdo & Fither side of vehirle & nk & 385 & 285 & & $H^{-}$ \\
\hline & Record: 14 & 4 & $1, \|$ & Show: $\sqrt{\text { All }}$ Sele & Reco & ds ( 0 out of 39 & Selected) & Options - & & & & & \\
\hline
\end{tabular}

Figure 6-7: Destination layer table

The line layer's table contains only the connections used by the location-allocation tool (Figure 6-8).

\begin{tabular}{|c|c|c|c|c|c|c|c|c|c|c|c|}
\hline \multicolumn{12}{|c|}{ 粗 Attributes of Lines } \\
\hline & ObjectID & Shape & Name & & OriginID & DestinationID & DestinationRank & Total_Minutes & Total_Shape_Lenght & Allocate_Units & $\triangle$ \\
\hline \multirow[t]{9}{*}{$\rightarrow$} & 23 & Polyline & Location 1 - Location 105 & & 1 & 105 & 23 & 3.998233 & $=0$ & & $1 \equiv$ \\
\hline & 41 & Polyline & Location 2 - Location 184 & & 2 & 184 & 8 & 2.958695 & 0 & & \\
\hline & 54 & Polyline & Location 2 - Location 199 & & 2 & 199 & 21 & 4.141043 & 0 & & 1 \\
\hline & 83 & Polyline & Location 3 - Location 102 & & 3 & 102 & 20 & 2.009172 & 0 & & 1 \\
\hline & 89 & Polyline & Location 3 - Location 176 & & 3 & 176 & 26 & 2.661367 & 0 & & 1 \\
\hline & 117 & Polyline & Location 4 - Location 101 & & 4 & 101 & 13 & 1.429077 & 0 & & \\
\hline & 140 & Polyline & Location 4 - Location 199 & & 4 & 199 & 36 & 4.206921 & 0 & & \\
\hline & 151 & Polyline & Location 5 - Location 88 & & 5 & 88 & 9 & 1.081583 & 0 & & 1. \\
\hline & Record: 14 & 4 & $\overline{1}, \|$ Show: All & Selected & Records (0 & It of 3458 Selected) & Options - & & & & \\
\hline
\end{tabular}

Figure 6-8: Lines layer table

Figure 6-9 shows the result of running the parking modeling tool.

\subsection{Summary}

This chapter discussed the results of the different scenarios used to analyze the relation between parking demand and supply within the time threshold. It also discussed the GIS tools developed to perform parking modeling. The final results were displayed in hardcopy maps. The next chapter will outline the conclusions of this project and future work. 



\section{Chapter 7 - Conclusions and Future Work}

The goal of this project was to provide tools to calculate unsatisfied parking demands and supplies using network analyst. To meet this goal, two tools were developed to process the data and perform location-allocation. This section discusses the outcome of the GIS tools and how they met the client's functional and non-functional requirements. It also describes possible future work.

\subsection{Conclusions}

Two tools were developed to automate the parking modeling process and prepare the data. The first GIS tool enables users to calculate the amount of parking demand based on the time of day, week, and year. The client's parking demand model was integrated with ArcGIS and tables were stored inside SQL Server to provide accessibility to tables inside and outside of the ArcGIS environment. The tool was developed using C\# and .NET to provide more flexible interface. Although the tool is easy to use, the user should be familiar with calculating parking demands procedures. The second GIS tool enables users to calculate unsatisfied parking demand and supplies using network analyst. The tool was developed using Python, and stored inside ArcGIS toolbox, which can be modified easily if needed. The method used for location-allocation was random selection; one of the benefits of using this method is that it increases the speed of calculation. All tools were tested and fully functional.

\subsection{Future work}

This project can be used as an initial building block for future projects. Provided in the following sections are possible extensions that could be of value to the parking modeling. The following sections discuss three potential tasks: using a pedestrian network, using other location-allocation models, and improving and updating tools.

\subsubsection{Using Pedestrian Network}

For future work, the project scope could be expanded to designing and implementing a pedestrian network. One of the advantages of making and providing a pedestrian network is using different kinds of location-allocation models. Performing an analysis on a pedestrian network increases accuracy of results.

\subsubsection{Using other location-allocation methods}

Recent developments in optimization research have yield technique for optimizing very large number of supplies and demands (Yang, 2010). Further extension of this work could investigate these alternative techniques. 


\subsubsection{Improving and update tools}

The tools were developed based on ArcGIS 9.3.1 because that was what the client requested. Future work could involve developing these tools based on ArcGIS 10. 


\section{Works Cited}

Axhausen, K. W., \& Polak, J. W. (1991). Choice of parking: Stated preference approach. Transportation, 18(1), 59-81. doi:10.1007/BF00150559

Cooper, L. (1963). Location-allocation problems. Operations Research, 11(3), 331-343.

Cooper, L. (1964). Heuristic methods for location-allocation problems. Siam Review, $6(1), 37-53$.

Institute of Transportation Engineers. (2010). Parking Generation. Washington, DC: Institute of Transportation Engineers.

Love, R. F., \& Juel, H. (1982). Properties and solution methods for large locationallocation problems. Journal of the Operational Research Society, 33(5), 443452.

Schietzelt, T. H., \& Densham, P. (2003). Location-allocation in GIS. Advanced spatial analysis: the CASA book of GIS, 345.

Shoup, D. C. (1999). The trouble with minimum parking requirements. Transportation Research Part A: Policy and Practice, 33(7-8), 549-574.

Van Der Waerden, P., Oppewal, H., \& Timmermans, H. (1993). Adaptive choice behaviour of motorists in congested shopping centre parking lots. Transportation, 20(4), 395-408.

Voith, R. (1998). The downtown parking syndrome: Does curing the illness kill the patient? Business Review, 1, 3-14.

Wong, S. C., Tong, C. O., Lam, W. C., \& Fung, R. Y. (2000). Development of parking demand models in Hong Kong. Journal of Urban Planning and Development, $126,55$.

Yang, X. (2010). Engineering Optimization: An Introduction with Metaheuristic Applications (1st ed.). Wiley.

Young, W. (2000). Modeling parking. In D. Hensher \& K. Button (Eds.), Handbook of transport modelling (Vol. 1, pp. 409-20). Oxford: Pergamon. 



\section{Appendix A. Location-Allocation}

\#return the filename, line number and error message in case of exception def Trace():

\#Get the traceback object

$\mathrm{tb}=$ sys.exc_info()[2]

\#Get the script name and line number from the trace back object

tbinfo $=$ traceback.format_tb(tb)[0]

line = tbinfo.split(", ")[1]

filename = os.path.join(sys.path[0],"montecarlo.py")

\#Get the python error

pyError $=$ traceback.format_exc( $)$.splitlines ()$[-1]$

return line,filename,pyError

\#Get all the sublayers from input NALayer

\#This will not work if using a NALayer as lyr file

def GetNAClasses(nalayer):

NAClasses $=\{\}$ \#Dict that stores NAClassName:NAClassLayerName key value pair desc $=$ gp.describe(nalayer)

sublayers $=$ desc . children

sublayers.reset()

sublayer $=$ sublayers.next ()

while sublayer:

NAClasses[sublayer.name.lower()] = sublayer.namestring

sublayer $=$ sublayers.next ()

return NAClasses

\#Deletes the inmemory datasets

def deleteNALayer(nalayer):

if gp.exists(nalayer):

gp.Delete_management(nalayer)

\#prints a GP message and writes the same message to a log file

def PrintAndWriteMessages(msg,severity $=0)$ :

if severity $==0$ :

gp.AddMessage(msg)

elif severity $==1$ :

gp.AddWarning $(\mathrm{msg})$

elif severity $==2$ :

gp.AddError(msg)

logfile.write(msg + "\n")

\#Exception returned by the LPPSolver

class LPSolverError(Exception):

pass 
\#import the modules

import arcgisscripting, sys, os, traceback, time, random

\#Create the Geoprocessor

$\mathrm{gp}=$ arcgisscripting.create $(9.3)$

\#Use the lowest available license when run as standalone script

if gp.ProductInfo().lower() == 'notinitialized':

products = ('Engine','ArcView', 'ArcEditor', 'EngineGeoDB','ArcInfo', 'ArcServer')

for level in range $(0$, len(products)):

if gp.CheckProduct(products[level]).lower() == 'available':

gp.SetProduct(products[level])

break

\#overwrite existing outputs

gp.OverwriteOutput $=$ True

\#Create a log file to contain messages in the same location as the script

logfile = open(os.path.join(sys.path[0],"OptimumAllocation_log.txt"),"w",0)

logfile.write("Start time: " + time.asctime ()$+$ "\n")

try:

\#Check out the network extension. Quit if not found

if gp.CheckExtension("network").lower() == "available":

gp.CheckOutExtension("network")

else:

sys.exit(1)

\#Create a progressor

gp.SetProgressor("step","Computing Optimum Allocation",0,14,1)

\#Get the supply and demand field names and origin and dest fc's

origin_fc_polygon $=$ gp.GetParameterAsText $(0)$

supplyfield $=$ gp.GetParameterAsText $(1)$

ratefield $=$ gp.GetParameterAsText $(2)$

dest_fc $=$ gp.GetParameterAsText(3)

demandfield $=$ gp.GetParameterAsText $(4)$

\#get the required inputs from the tool dialog to create the OD layer

nds $=$ gp.GetParameterAsText $(5)$

impedance $=$ gp.GetParameterAsText(6)

impedance_cutoff = gp.GetParameterAsText(7)

netlayer $=$ gp.GetParameterAsText $(8)$

usehir = gp.GetParameterAsText $(9)$

uturn_policy = gp.GetParameterAsText(10) 
restrictions $=$ gp.GetParameterAsText $(11)$

search_tolerance $=$ gp.GetParameterAsText(12)

msg $=$ "Convert Parking Demand from polygon to point feature"

PrintAndWriteMessages $(\mathrm{msg}, 0)$

gp.SetProgressorLabel $(\mathrm{msg})$

\#Convert ParkingDemand from polygon feature to point feature

\#gp.FeatureToPoint origin_fc_polygon, origin_fc, "CENTROID"

origin_fc $=$ origin_fc_polygon

msg = "Creating a new OD Cost Matrix Layer"

PrintAndWriteMessages(msg,0)

gp.SetProgressorLabel(msg)

\# describe the nds to get value of accumulators parameter

\# we wish to accumulate all of the cost attributes

desc $=$ gp.describe(nds)

attrUnits $=\{\}$

accumulators $=" "$

attributes $=$ desc. attributes

attributes.reset()

attribute $=$ attributes.next ()

while attribute:

if attribute.UsageType == "Cost":

accumulators += attribute.Name + ";"

attrUnits[attribute.Name] $=$ attribute.Units

attribute $=$ attributes.next ()

accumulators $=$ accumulators.rstrip $(" ; ")$

\#get and set the optional parameters to create the OD layer

if impedance_cutoff $=="$ ":

impedance_cutoff $==$ "\#"

if usehir.lower() == 'true':

hierarchy = "USE_HIERARCHY"

else:

hierarchy = "NO_HIERARCHY"

\#Create a new OD Costmatrix layer

gp.MakeODCostMatrixLayer(nds,netlayer,impedance,impedance_cutoff,"\#",accumulator s,uturn_policy,restrictions,hierarchy,"\#","STRAIGHT_LINES")

\#Add the supply and demand fields

gp.AddFieldToAnalysisLayer_na(netlayer,"Origins","Supply","Double")

gp.AddFieldToAnalysisLayer_na(netlayer,"Destinations","Demand","Double") 
gp.AddFieldToAnalysisLayer_na(netlayer,"Origins","CostAtOrigin","Double")

gp.AddFieldToAnalysisLayer_na(netlayer,"Lines","Total_CostAtOrigin","Double")

gp.SetProgressorPosition()

\#Load Origins and Destinations in NALayer along with values from Supply and demand fields

\#Field map is "FieldSrc FieldTarget \#; FieldSrc FieldTarget \#"

msg = "Loading Origins"

PrintAndWriteMessages $(\mathrm{msg}, 0)$

gp.SetProgressorLabel(msg)

\#if no ratefield is specified use a constant rate value of 1

useRate $=$ True

if ratefield $=="$ ":

useRate $=$ False

if useRate:

Origin_FieldMap = "Supply " + supplyfield + " \#" + ";" + "CostAtOrigin " + ratefield + "\#" + ";" + " Name Name \#; CurbApproach \# 0"

else:

Origin_FieldMap = "Supply " + supplyfield + " \#" + ";" + "CostAtOrigin \# 1" + ";"

+ " Name Name \#; CurbApproach \# 0"

gp.AddLocations(netlayer,"Origins",origin_fc,Origin_FieldMap,search_tolerance)

gp.SetProgressorPosition()

msg = "Loading Destinations"

PrintAndWriteMessages(msg,0)

gp.SetProgressorLabel(msg)

Dest_FieldMap = "Demand " + demandfield + " \#" + "; CurbApproach \# 0; Name Name \#"

gp.AddLocations(netlayer,"Destinations",dest_fc,Dest_FieldMap,search_tolerance) gp.SetProgressorPosition()

\#Solve the od layer. Error out if there is invalid location by using HALT option of Solve

msg $=$ "Solving the OD Cost Matrix"

PrintAndWriteMessages $(\mathrm{msg}, 0)$

gp.SetProgressorLabel(msg)

gp.Solve(netlayer,"HALT")

gp.SetProgressorPosition()

msg = "\tStep1: Getting all the layers...."

PrintAndWriteMessages $(\mathrm{msg}, 0)$

gp.SetProgressorLabel(msg.lstrip('ไt')) 
\# Get the OD matrix sub layers from entire analysis layer.

odnaclasses $=$ GetNAClasses(netlayer)

odmatrix = odnaclasses["odlines"]

originlayer $=$ odnaclasses ["origins"]

destlayer $=$ odnaclasses ["destinations"]

\# Add the field to store the optimal allocation of units after TP is solved

gp.AddField_management(odmatrix,"Allocate_Units","Long")

msg = "\tStep2: Getting all the supplies...."

PrintAndWriteMessages(msg,0)

gp.SetProgressorLabel(msg.lstrip('|t'))

\#get the supply for all the origins by using the origins layer in OD matrix layer origincur $=$ gp. UpdateCursor(originlayer)

\#Store the supply in a dict with key value as ObjectID which is Origin ID in matrix layer

supplydict $=\{\}$

\#making the used supply in a dict with key value as ObjectID which is Origin ID in matrix layer with defalt value 0

usedsupplydict $=\{\}$

row $=$ origincur.next ()

while row:

cost $=$ row.GetValue("Supply")

oid = str(row.GetValue("OBJECTID"))

supplydict[oid] $=$ cost

usedsupplydict[oid] $=0$

row $=$ origincur.next ()

del origincur, row

msg = "\tStep3: Getting all the demands...."

PrintAndWriteMessages(msg,0)

gp.SetProgressorLabel(msg.lstrip('It'))

\#get the demand for all the destinations by using the Destinations layer in OD matrix solver

destincur $=$ gp.UpdateCursor(destlayer)

\#Store the demand in a dict with key value as ObjectID which is destination ID in

matrix layer

demanddict $=\{\}$

\#making the used supply in a dict with key value as ObjectID which is Origin ID in matrix layer with defalt value 0

useddemanddict $=\{\}$ 


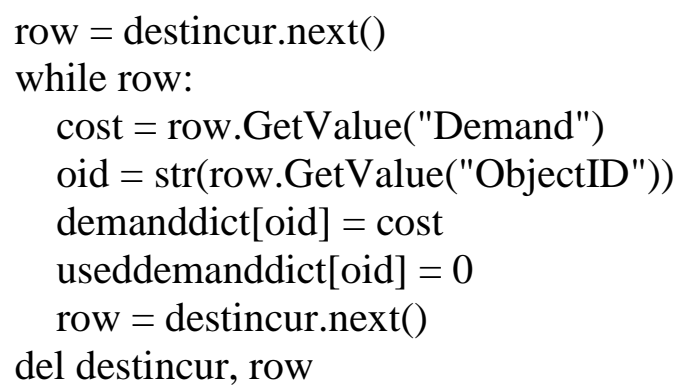

\#Calculate the new Total_CostAtOrigin by getting the transport rate from origins and multiplyng by Total_Impedance

\#For this transfer the CostAtOrigin from Origins to Lines

\#Add the join

gp.AddJoin_management(odmatrix, "OriginID", originlayer, "ObjectID", "KEEP_ALL")

\#Calculate the field

field_expression = "!ODLines.Total_" + impedance + "! * !Origins.CostAtOrigin!" gp.CalculateField_management(odmatrix, "ODLines.Total_CostAtOrigin", field_expression, "PYTHON", "\#")

\#Remove the join

gp.RemoveJoin_management(odmatrix, "Origins")

\#Get the cursor for all record in the matrix.

odmatrixcur $=$ gp.UpdateCursor(odmatrix)

\#Create an empty dictionary to contain all the decision variables. i.e all OD pairs and associated transport cost

costdict $=\{\}$

\#making the used cost in a dict with key value as OD pairs with defalt value 0 usedcostdict $=\{\}$

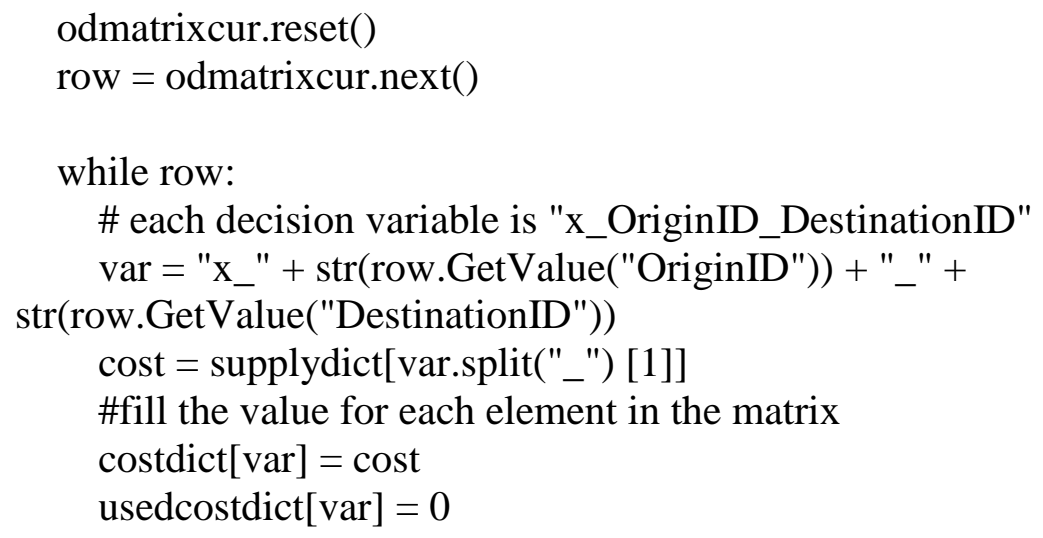




$$
\text { row }=\text { odmatrixcur.next }()
$$

\#create a backup form costdict

backcostdict $=$ costdict

del odmatrixcur, row

\section{gp.SetProgressorPosition()}

msg = "\tStep5: Choosing Random OD pairs...."

PrintAndWriteMessages(msg,0)

gp.SetProgressorLabel(msg.lstrip('ไt'))

\#Create a list of keys from OD pairs

costdictkeys $=$ costdict.keys $($ )

\#Create an empty list to contain random choice of OD pairs costdictrandom $=[]$

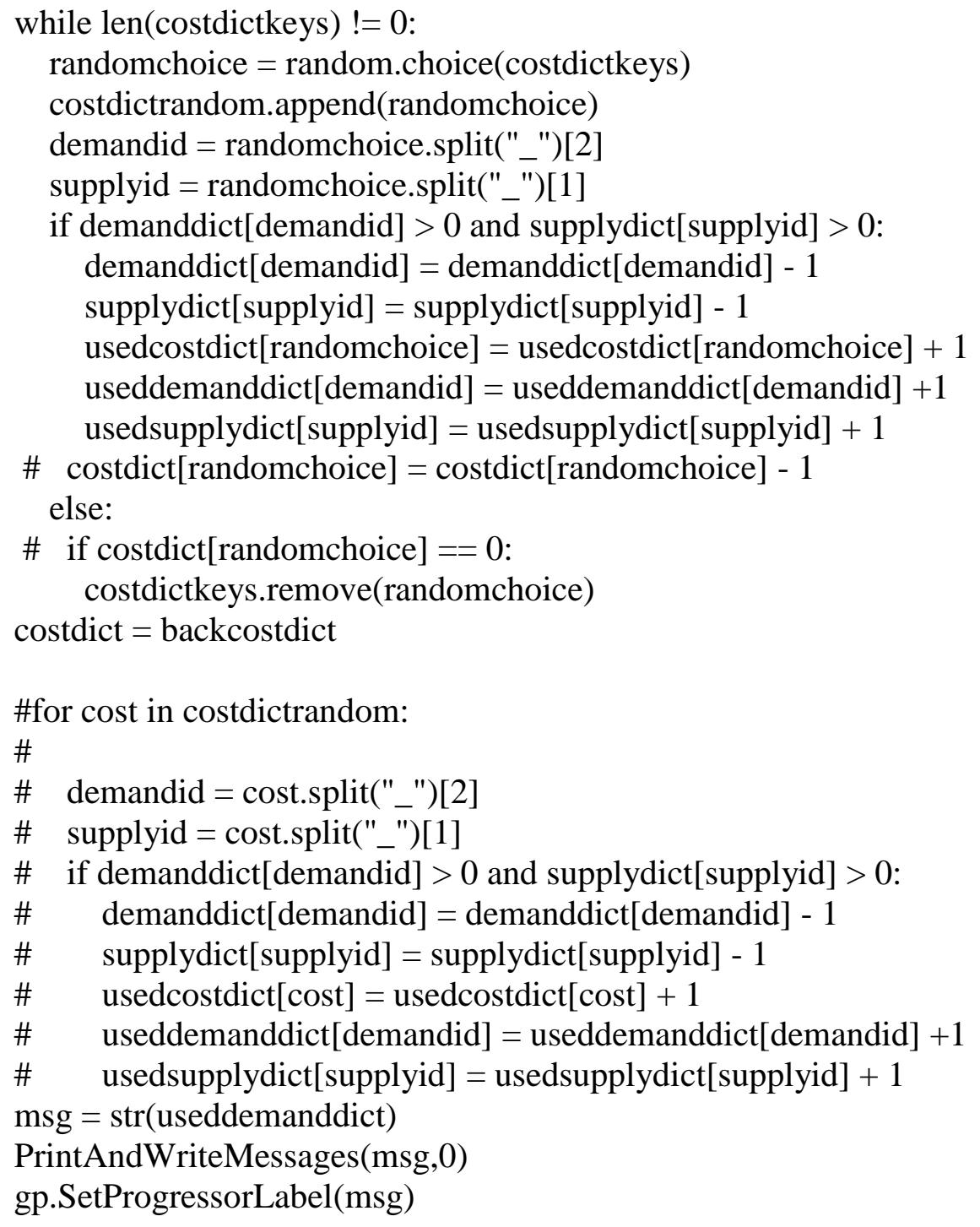




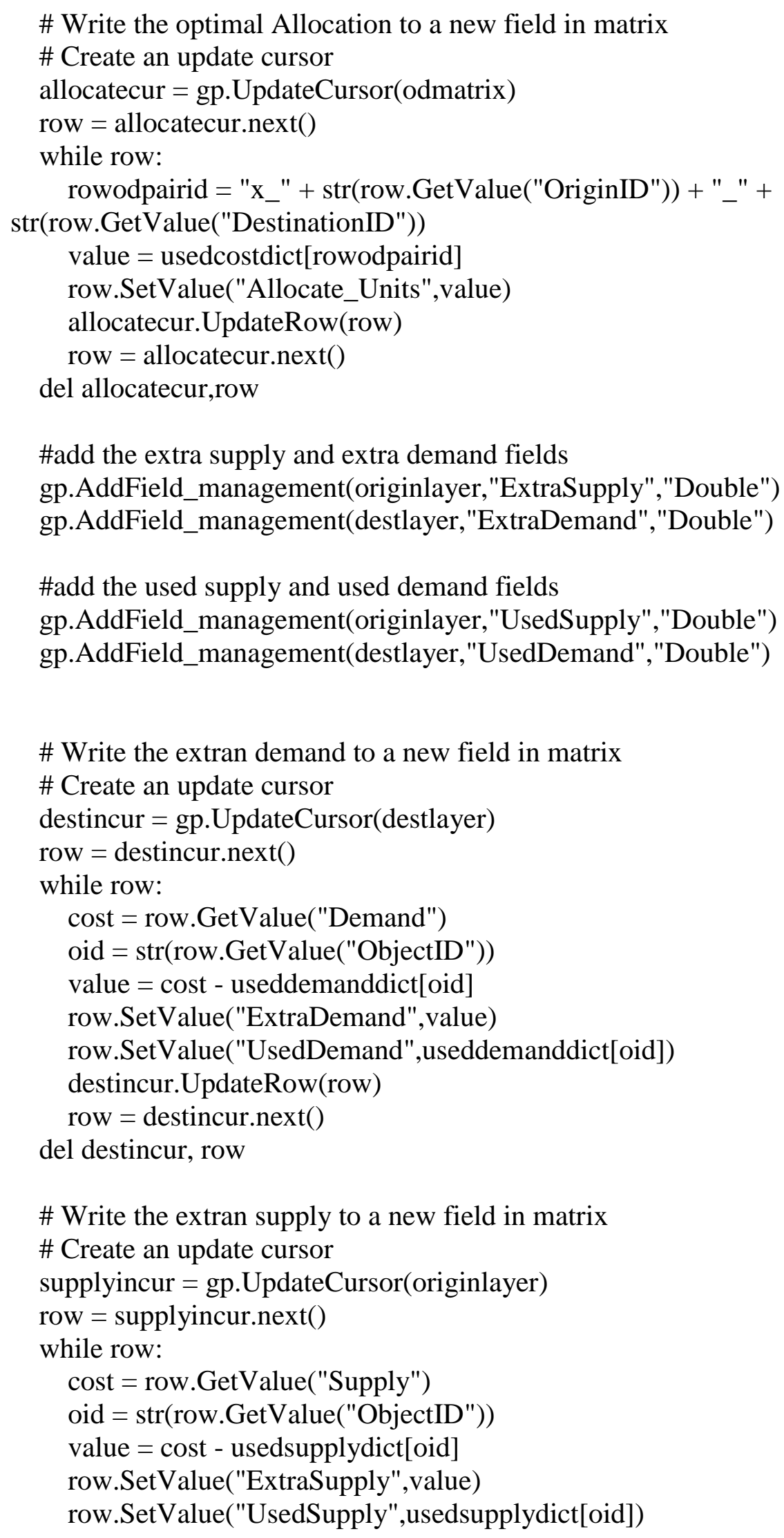


supplyincur.UpdateRow(row)

row = supplyincur.next ()

del supplyincur, row

\#Delete OD lines from the matrix where there is no allocation

gp.SelectLayerByAttribute_management(odmatrix,"NEW_SELECTION", 'Allocate_Units $=0$ ')

gp.DeleteRows_management(odmatrix)

gp.SetProgressorPosition()

\#Add the output OD layer to ArcMap TOC

gp.SetParameterAsText(13,netlayer)

except arcgisscripting.ExecuteError:

\#Handle GP specific errors

line, filename, err $=$ Trace ()

msg = "Geoprocessing error on " + line + " of " + filename + " :" + "In" + gp.GetMessages(1) + gp.GetMessages(2)

PrintAndWriteMessages(msg,2)

deleteNALayer(netlayer)

except ImportError:

\#Handle pulp import error

msg = "Pulp module not installed."

PrintAndWriteMessages(msg,2)

msg = "Download and install Pulp from http://code.google.com/p/pulp-or"

PrintAndWriteMessages(msg,1)

except SystemExit:

\#Handle system exit when sys.exit() is called

msg = "Network Analyst license not found"

PrintAndWriteMessages(msg,2)

except:

\#Handle Python errors

line, filename, err $=$ Trace ()

msg = "Python error on " + line + " of " + filename + "\n" + err

PrintAndWriteMessages(msg,2)

deleteNALayer(netlayer)

finally:

\#Close the log file with a closing time stamp

logfile.write("End Time: " + time.asctime())

logfile.close() 
